\title{
A model for the electrical conductivity of peak aged and overaged Al-Zn-Mg-Cu Alloys
}

\author{
M. J. Starink and X.M. Li \\ Materials Research Group, School of Engineering Sciences, \\ University of Southampton, Southampton SO 171 BJ, UK
}

\begin{abstract}
A physically-based model for the electrical conductivity of peak aged and overaged Al-Zn-Mg-Cu (7xxx series) alloys is presented. The model includes calculations of the $\eta$ and the S phase solvus (using a regular solution model), taking account of the capillary effect and $\eta$ coarsening. It takes account of the conductivity of grains (incorporating dissolved alloying elements, undissolved particles and precipitates) and solute depleted areas at the grain boundaries. Data from optical microscopy, differential scanning calorimetry (DSC), scanning electron microscopy (SEM) along with energy dispersive X-ray spectrometry (EDS), and transmission electron microscopy (TEM) are consistent with the model and its predictions. The model has been successfully used to fit and predict the conductivity data of a set of 7xxx alloys including both Zr containing alloys and Cr containing alloys under various ageing conditions, achieving an accuracy of about $1 \%$ in predicting unseen conductivity data from this set of alloys.
\end{abstract}

\section{Introduction}

\subsection{Aims and scope}

Yield strength, toughness and stress-corrosion cracking (SCC) resistance are the three major properties of heat-treatable high strength 7xxx aluminium alloys (Al-Zn-Mg based), when used in upper wing aircraft structures $[1,2,3,4,5]$. Whilst the SCC resistance is relatively difficult to be quantitatively assessed, the electrical conductivity, however, can be used as a measure of the SCC resistance. The SCC resistance has been found to increase with increasing electrical conductivity in 7xxx series alloys, particularly from near peak-aged (T6) to the overaged (T73) condition [6,7,8]. Consequently, the study of electrical conductivity of $7 \mathrm{xxx}$ alloys has been of key interest to industrial manufacturers as well as material scientists, with an aim to predict and improve the stress corrosion performance.

Several models or elements of models for the dependence of conductivity of Al-based alloys on composition and heat treatment have been reported [9,10,11,12,13]. For instance, a general description of thermodynamics of the $\mathrm{Al}$ alloy system and the kinetics of phase precipitation (based on JMAK kinetics [14]) was given by Bratland et al [9]. A model that predicts conductivity as a function of the microstructure was proposed by Guyot and Cottignies [10]. This model considered conductivity increase on overageing due to the reduction in electron scattering resulting from the coarsening of precipitates at constant 
volume fraction, and the model was applied to one 7xxx alloy. In contrast, Dorward [11] proposed a model that considered conductivity increase on overageing due to the reduction in the amount of dissolved atoms resulting from the coarsening of precipitates, and the model was applied to one 7xxx alloy (a 7050 alloy) for three ageing temperatures. Femminella and co-workers [12,13] used adaptive numerical (AN) approaches to model the electrical conductivity of nine 7xxx alloys. The results showed that with adaptive numeric modelling approaches the electrical conductivity could be modelled very well. The latter paper is the first publication describing modelling of conductivity in a multitude of alloys.

For modelling the conductivity of 7xxx alloys to be possible in terms of physical and metallurgical principles, the microstructure of this kind of alloy needs to be analysed. For instance, the grain and subgrain structure, the precipitation sequences, precipitate free zones (PFZ) as well as intermetallic particles of the alloys need to be characterised. In the present paper a detailed model for the electrical conductivity of 7xxx aluminium alloys under various ageing conditions will be presented. The model will be used to model and predict the conductivity of a wide range of $7 \mathrm{xxx}$ alloys, which fall mostly within the composition windows of 7010, 7x50 and 7x75 aerospace alloys (see Table 1).

\subsection{Metallurgy of 7xxx Alloys}

Most 7xxx alloys can be categorized in two groups depending on the type of grain structure controlling element that is added. $\mathrm{Zr}$ containing alloys will contain $\beta^{\prime}$ phase $\left(\mathrm{Al}_{3} \mathrm{Zr}, \mathrm{L}_{2}\right.$ structure) particles, whilst $\mathrm{Cr}$ containing alloys will generally contain $\mathrm{Al}_{7} \mathrm{Cr}$ particles. In aluminium metallurgy, these grain structure controlling particles are generally called dispersoids. The type of dispersoids will influence the recrystallisation and quench sensitivity of the alloy.

The precipitation in Al-Zn-Mg-Cu alloys involves three possible precipitation sequences, with the relative importance depending on composition $[15,16,17]$. The main sequence, involving mostly $\mathrm{Mg}$ and $\mathrm{Zn}$ is thought to dominate hardening in most 7xxx alloys:

$$
\mathrm{SSS} \alpha \rightarrow \text { GP zones } \rightarrow \eta^{\prime} \rightarrow \eta
$$

A second one occurs usually at $\mathrm{T}>200^{\circ} \mathrm{C}$ and involves the $\mathrm{T}$ phase [18]:

$$
\mathrm{SSS} \alpha \rightarrow \mathrm{T}
$$

A third one involves exclusively $\mathrm{Cu}$ and $\mathrm{Mg}$ :

$$
\mathrm{SSS} \alpha \rightarrow \mathrm{S}
$$

where SSS $\alpha$ represents supersaturated solid solution, GP zones are Guinier Preston zones, $\eta$ is a quaternary phase formed by solid solution of $\mathrm{MgZn}_{2}$ with $\mathrm{AlCuMg}$ components (i.e. 
$\mathrm{Mg}(\mathrm{Zn}, \mathrm{Al}, \mathrm{Mg})_{2}$ or $\mathrm{Mg}(\mathrm{Zn}$, $\left.\mathrm{AlMg})\right)$ [19], $\mathrm{T}$ is a quaternary phase based on $\mathrm{Mg}_{3} \mathrm{Zn}_{3} \mathrm{Al}_{2}$, $\mathrm{S}$ is $\mathrm{Al}_{2} \mathrm{CuMg}$.

In Al-Zn-Mg-Cu alloys, GP zones have an approximately spherical shape. The intermediate precipitate $\eta^{\prime}$ and the equilibrium precipitate $\eta$ are thought to have the same hexagonal structure although the lattice parameters are different [20]. The semicoherent $\eta^{\prime}$ may form from GP zones, and presents the following orientation relationship with the matrix [21]: $(0001)_{\eta^{\prime}} / /(111)_{\alpha}$ and $(12 \overline{10})_{\eta^{\prime}} / /(110)_{\alpha}$. The incoherent $\operatorname{MgZn}_{2}(\eta)$ forms at or from $\eta^{\prime}$ as laths or plates.

It has been shown that the precipitate phases occurring in 7xxx alloys depend on the type of ageing treatments, whilst also compositional variations may have some influence. In general, in the peak-aged condition (T6), the main precipitate phase is $\eta^{\prime}$, whilst in overaged conditions (T7) the main precipitate phases are $\eta$ or a mixture of $\eta^{\prime}$ and $\eta$ [22,23]. A number of researchers have indicated that the electrical resistivity (the reciprocal of conductivity) of $\mathrm{Al}$ alloys is dependent on the concentration of atoms in solid solution [24,25,26]. The effect of dissolved alloying elements on the electrical resistivity of a metallic alloy is thought to be linear and additive, this is the so-called Matthiesen's rule [26]. In terms of the relevance and importance of the concentration of dissolved atoms in the matrix, the precipitation in 7xxx alloys and the resulting microstructures will significantly influence the change of conductivity as ageing proceeds.

\section{Experimental Methods}

\subsection{Materials}

To validate models, conductivity data from a database of conductivies of $14 \mathrm{Al}-\mathrm{Zn}-\mathrm{Mg}-\mathrm{Cu}$ alloys aged for various times at a $172^{\circ} \mathrm{C}$ after heating at $20^{\circ} \mathrm{C} / \mathrm{h}$ to the ageing temperature is used. All alloys were produced at QinetiQ (formerly DERA), Farnborough, UK. The alloys were processed using conventional casting procedures, and after stress relaxation and homogenisation, the ingots were divided into two halves. Each of the halves was hot worked in several stages, the final stage was hot rolling to $25 \mathrm{~mm}$ thick plates of about 1 meter length and $0.2 \mathrm{~m}$ width. The alloys were solution treated at $475^{\circ} \mathrm{C}$ for $1 \mathrm{~h}$ and quenched and subsequently aged. The chemical compositions of the alloys were measured by optical emission spectroscopy (OES) and compositions of selected alloys are presented in the results section and the figures. (Some of the composition data in the database is confidential.) There are two groups of alloys, one consists of alloys that contain $\mathrm{Zr}$ as dispersoid forming element and the second group consists of alloys which contain $\mathrm{Cr}$ as dispersoid forming element. Nine Zr-containing alloys and five Cr-containing alloys are studied. The compositions of the $\mathrm{Zr}$ containing alloys fall broadly within in the range of typical $\mathrm{Zr}$ containing aerospace alloys 7010, 7x50 and 7040 (for composition ranges see Table 1, some of the present alloys have $\mathrm{Cu}$ contents slightly lower and $\mathrm{Mg}$ contents slightly higher than these composition ranges) and compositions of the $\mathrm{Cr}$ containing alloys fall within the composition range of the $\mathrm{Cr}$ containing alloy $7 x 75$. The nine Zr-containing alloys contain $0.02 \% \mathrm{Ti}$ and $0.12 \% \mathrm{Zr}$ (all in wt $\%$ ). The five Cr-containing alloys contain $0.02 \% \mathrm{Ti}$ and $0.2 \% \mathrm{Cr}$. For all alloys, $99.90 \%$ aluminium was used as base to ensure comparable, low impurity contents. Measured Fe 
contents of the alloys are between 0.05 and $0.08 w t \%$ and Si contents are between 0.02 and $0.03 w t \%$.

Table 1 Compositions of alloys referred to in this work. (wt\%)

\begin{tabular}{|l|l|l|l|l|l|l|l|l|l|}
\hline Alloy & $\mathrm{Zn}$ & $\mathrm{Mg}$ & $\mathrm{Cu}$ & $\mathrm{Zr}$ & $\mathrm{Cr}$ & $\mathrm{Ti}$ & $\mathrm{Mn}$ & $\mathrm{Fe}$ & $\mathrm{Si}$ \\
\hline 7010 & $5.7-6.7$ & $2.1-2.6$ & $1.5-2.0$ & $0.10-0.16$ & $<0.05$ & $<0.06$ & $<0.10$ & $<0.15$ & $<0.12$ \\
\hline 7040 & $5.7-6.7$ & $1.7-2.4$ & $1.5-2.3$ & $0.05-0.12$ & $<0.04$ & $<0.06$ & $<0.04$ & $<0.13$ & $<0.10$ \\
\hline 7050 & $5.7-6.7$ & $1.9-2.6$ & $2.0-2.6$ & $0.10-0.15$ & $<0.04$ & $<0.06$ & $<0.10$ & $<0.15$ & $<0.12$ \\
\hline 7150 & $5.9-6.9$ & $2.0-2.7$ & $1.9-2.5$ & $0.08-0.15$ & $<0.04$ & $<0.06$ & $<0.10$ & $<0.15$ & $<0.12$ \\
\hline 7075 & $5.1-6.1$ & $2.1-2.9$ & $1.2-2.0$ & $<0.05$ & $0.18-0.28$ & $<0.2$ & $<0.3$ & $<0.5$ & $<0.4$ \\
\hline 7475 & $5.2-6.2$ & $1.9-2.6$ & $1.2-1.9$ & $<0.05$ & $0.18-0.25$ & $<0.06$ & $<0.06$ & $<0.12$ & $<0.10$ \\
\hline
\end{tabular}

\subsection{Microstructural Analysis}

Representative microstructures of the alloys are studied by using optical microscopy, differential scanning calorimetry (DSC), scanning electron microscopy (SEM) along with energy dispersive X-ray spectrometry (EDS) and transmission electron microscopy (TEM) techniques.

A digital image analysis software package linked to an optical microscope was employed for analysis of grain structure and particles in the samples. Each alloy was cut at about half thickness along the three main planes, i.e. the LT, TS and LS planes ( $\mathrm{L}=$ longitudinal rolling direction, $\mathrm{T}=$ long transverse and $\mathrm{S}=$ short transverse). Specimens were ground and subsequent polishing was performed using $6 \mu \mathrm{m}, 1 \mu \mathrm{m}$ and finally $1 / 4 \mu \mathrm{m}$ diamond paste. For grain structure examination, samples were etched in $10 \mathrm{~cm}^{3} \mathrm{H}_{3} \mathrm{PO}_{4}$ plus $90 \mathrm{~cm}^{3}$ distilled water at $50^{\circ} \mathrm{C}$ for one minute. For a more detailed investigation of grain structure, selected specimens were studied using electron backscatter diffraction (EBSD). The EBSD specimens were ground and polished and subsequently electro-polished using a solution of $33 \% \mathrm{HNO}_{3}$ and $67 \%$ methanol at a temperature of $-30^{\circ} \mathrm{C}$. Orientation measurements were taken in a JEOL FEG-SEM 6500F using an automated EBSD system (Channel 5 software from HKL, Denmark). Step size was 1 or $2 \mu \mathrm{m}$. Success rate of identification of Kikuchi patterns was 80-90\%.

Other SEM work was conducted on a Jeol JSM-6400 SEM. Mostly backscattered electron mode was used. Different areas on the TS sections were scanned to reveal the existing particles. Chemical compositions of various particles in the samples were measured using EDS. The TEM facility was a JEOL JEM 2000FX transmission electron microscope. The TEM samples were prepared by cutting a thin slice $(\sim 0.3 \mathrm{mmm})$, punching a $0.3 \mathrm{~mm}$ diameter disc and grinding it to a thickness of about $0.15 \mathrm{~mm}$. The electropolishing solution was $70 \%$ methanol and $30 \%$ nitric acid, maintained at a temperature of between $-20^{\circ} \mathrm{C}$ and $-30^{\circ} \mathrm{C}$. 
A Shimadzu DSC-50 (heat-flux type) was employed for the Differential Scanning Calorimetry (DSC) experiments. The DSC samples were machined from the 7xxx plates to $5 \mathrm{~mm}$ in diameter and $1 \mathrm{~mm}$ in thickness with average mass of about $63 \mathrm{mg}$. A pure aluminium reference $(99.9 \%)$ with a mass and shape close to that of the sample was used. The heating rate was $10^{\circ} \mathrm{C} / \mathrm{min}$. Further details of the DSC experimental procedures are presented elsewhere [22,27]. Presented DSC curves show the heat flows after correction for baseline and heat capacity effects, i.e. they represent the heat flow due to reactions in the sample, with the horizontal line of zero heat flow representing points where no net heat flow due to reactions occurs.

\subsection{Conductivity Measurement}

All conductivity measurements were performed at QinetiQ (formerly DERA). Electrical conductivity test blocks were extracted from the treat-treated plates to provide milled surfaces at the half thickness (T/2) position. The conductivity measurements were obtained using an AutoSigma 2000 instrument. For each composition / heat treatment combination a single test block was prepared, and each reported conductivity value is the average of 3 measurements performed on different locations of the test block. Care was taken to ensure that the test blocks are at laboratory temperature prior to measurement. In this paper we will present conductivity data as percentage International Annealed Copper Standard (\%IACS), which is the common industry standard for conductivity. (1\%IACS equals $5.8010^{5} \Omega^{-1} \cdot \mathrm{m}^{-1}$ )

\section{The Conductivity Model}

The conductivity model is based on the microstructure and microstructural development. The model considers that the alloy consists of two zones: the grains and the solute depleted areas (SDAs) around the grain boundaries. The respective conductivities of these two zones will be indicated as $\sigma_{G}$ and $\sigma_{S D A}$. We will approximate the grain by a single rectanguloid shape, with sizes $d_{L}, d_{T}$ ( $\mathrm{L}$ and $\mathrm{T}$ stand for longitudinal and transversal, respectively). The schematic graph of the structure of the alloy in the model is presented in Fig. 1. In general, the conductivity of the grain increases with ageing time due to precipitation of solute elements from the Al-rich phase, however, the overall conductivity is further influenced by growth of the SDA around the grain boundary, which occurs due to the formation and growth of grain boundary precipitates. We will discuss these two conductivity contributions in detail below.

\subsection{Combining the grain and SDA resistivity}

The calculation of the electrical resistivity of the alloy can be illustrated with an electrical schematic of the current flow taking account of the grains and the solute depleted areas around the grain boundaries. Such a schematic is presented in Fig. 2 for the T and $\mathrm{L}$ directions. For simplicity it is assumed that the resistivity of the SDA can be presented as a zone with uniform resistivity. From Fig. 2, it follows that for the current in the T direction: 


$$
R_{t o t}=\left(\frac{1}{R_{G}+R_{B, L}}+\frac{1}{R_{B, T}}\right)^{-1}
$$

where $R_{t o t}$ is the total resistivity, $R_{B, L}$ is the resistivity of the SDA around the grain boundary in the L direction, $R_{B, T}$ is the resistivity of the SDA around the grain boundary in the T direction, and $R_{G}$ is the resistivity of the grain.

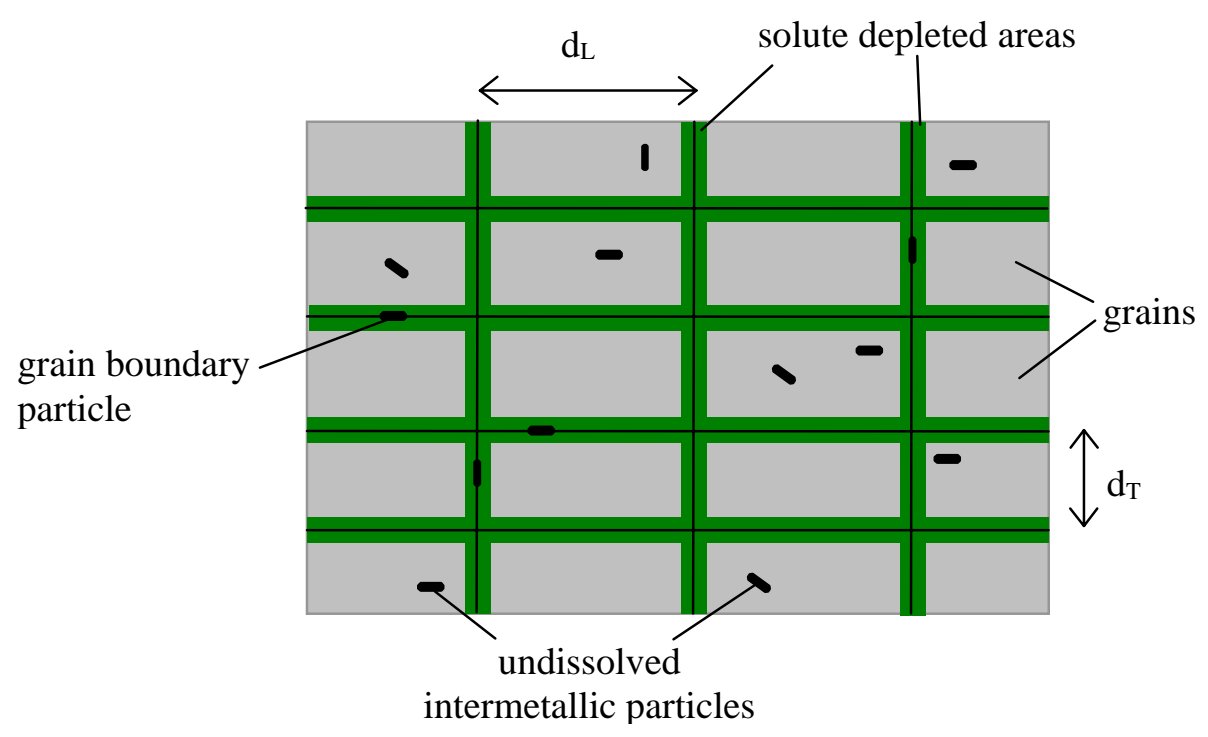

Fig. 1 Schematic graph of the structure of the alloy used in the model. Grains are rectanguloids and SDA around the grain boundary provide connected paths in the shape of plates.

Current in the $\mathrm{T}$ direction Current in the $\mathrm{L}$ direction
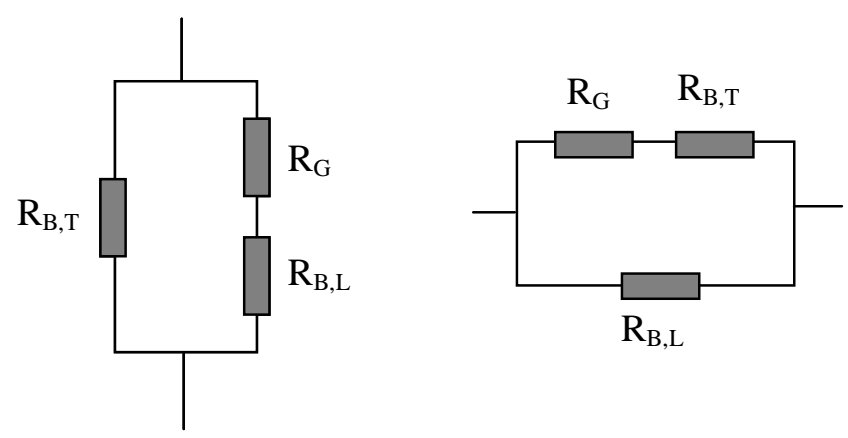

Fig. 2 Schematic current flow in the $\mathrm{T}$ and $\mathrm{L}$ directions

Division by $R_{G}$ yields:

$$
\frac{R_{t o t}}{R_{G}}=\left(\frac{1}{1+R_{B, L} / R_{G}}+\frac{1}{R_{B, T} / R_{G}}\right)^{-1}
$$


From the latter equation, it follows:

$$
\frac{\sigma_{t o t}}{\sigma_{G}}=\left(\frac{1}{1+R_{B, L} / R_{G}}+\frac{1}{R_{B, T} / R_{G}}\right)
$$

where $\sigma_{t o t}$ is the total average conductivity. These expressions are valid for grain structures in which all grains are of (approximately) equal dimensions, and should thus be suitable for alloys which are either completely unrecrystallised or completely recrystallised. For partially recrystallised alloys we will calculate the conductivity by taking the weighted average of unrecrystallised and recrystallised areas (weighted by volume fractions).

The effective resistivity of the grain boundary is approximated on the basis of a onedimensional diffusion model for diffusion of one element. Diffusivity data of $\mathrm{Zn}, \mathrm{Mg}$ and $\mathrm{Cu}$ [28] indicates that at the temperatures concerned $\left(100-200^{\circ} \mathrm{C}\right)$ the diffusivities decrease in the order $D_{Z n}, D_{M g}, D_{C u}$. The grain boundary precipitates are thought to be mainly $\eta$ phase, which can form as a ternary phase with composition close to $(\mathrm{Al}, \mathrm{Zn})_{2} \mathrm{Mg}$ but can also contain a limited amount of $\mathrm{Cu}[19,27]$. As $\mathrm{Cu}$ content is limited we expect that $\mathrm{D}_{\mathrm{Mg}}$ is the ratecontrolling factor ${ }^{*}$. Using this, the effective depth of solute depletion is approximately equal to $\sqrt{D_{M g} t}$ [29]. As diffusion process occurs along two sides of the grain boundary, the total width of the solute depleted area, $d_{s d a}$, can thus be estimated as $2 \sqrt{D_{M g} t}$.

The local conductivity in the solute depleted area (SDA) will depend on the distance to the grain boundary (GB): at the GB, most alloying elements will move to the GB precipitates, and the conductivity will approach a (semi-)equilibrium value equal to that of the alloy after precipitation of the precipitation hardening elements, $\sigma_{0}$, but at locations several times $\mathrm{d}_{\text {sda }}$ away from the GB, conductivity will approach the conductivity of the grains, $\sigma_{G}$. In first approximation, the average conductivity of the SDA around the grain boundary, $\sigma_{B}$, may be estimated to equal $\left(\sigma_{G}+\sigma_{0}\right) / 2$. Assuming that the resistance of the SDA can be characterised by an effective thickness and an average conductivity, would lead to:

$$
\frac{R_{B, L}}{R_{G}}=\frac{d_{L}}{2 d_{s d}(t)} \frac{\sigma_{G}(t)}{\sigma_{S D A}}
$$

However, the approximation leading to the latter equation is somewhat crude, and a more accurate treatment is the following. Consider a grain in the shape of a plate that has a thickness, $a$, that is very small in comparison to the two other main directions. If solute loss

\footnotetext{
* As $D_{C u}$ is lower than $D_{Z n}$ and $D_{M g}$, we might expect that in the early stages of their formation the grain boundary precipitates will be close to $(\mathrm{Al}, \mathrm{Zn})_{2} \mathrm{Mg}$ and that in later stages $\eta$ phase increases its Cu content. In the first stage, the diffusion of Mg would be the rate controlling factor because $D_{M g}<D_{Z n}$ and in later stages both $D_{M g}$ and $D_{C u}$ will have an influence. For the present treatment we have made the simplifying assumption that throughout $D_{M g}$ is the rate-controlling factor. We will see in section 4.2 that Cu dissolved in the Al-rich phase has a much smaller effect on conductivity as compared to Mg dissolved in the Al-rich phase, and this will tend to limit possible deviations introduced by this simplifying approximation.
} 
of the $\mathrm{Al}$ rich phase occurs only to the grain boundary, the average solute concentration is given as [30]:

$$
\frac{c_{M}-\bar{c}(t)}{c_{M}-c(t=\infty)}=1-\frac{8}{\pi^{2}} \sum_{j=0}^{\infty}(2 j+1)^{-2} \exp \left[-\frac{(2 j+1)^{2} \pi^{2} D t}{a^{2}}\right] \cong \frac{4}{a} \sqrt{\frac{D t}{\pi}}
$$

Where the latter approximation is accurate providing $d_{S D A}<a$. As resistivity is proportional to the solute concentration the resistivity in the direction of the plates of a microstructure consisting of these long plates is given by:

$$
\frac{\rho_{M}-\bar{\rho}(t)}{\rho_{M}-\rho(t=\infty)}=1-\frac{8}{\pi^{2}} \sum_{j=0}^{\infty}(2 j+1)^{-2} \exp \left[-\frac{(2 j+1)^{2} \pi^{2} D t}{a^{2}}\right] \cong \frac{4}{a} \sqrt{\frac{D t}{\pi}}
$$

In the latter equation we can approximate $\rho(t=\infty)$ by the resistivity of pure aluminium, and hence it follows:

$$
\frac{\bar{\rho}(t)}{\rho_{M}} \cong 1-\left[1-\frac{\rho_{\text {pure }}}{\rho_{M}}\right] \frac{4}{a} \sqrt{\frac{D t}{\pi}}
$$

or

$$
\frac{\sigma_{M}}{\sigma(t)} \cong 1-\left[1-\frac{\sigma_{M}}{\sigma_{\text {pure }}}\right] \frac{4}{a} \sqrt{\frac{D t}{\pi}}
$$

This treatment of the influence of the SDA on conductivity can be further refined by considering rectanguloid grains of finite dimensions using the treatment of diffusion in these shapes outlined in Ref. [30]. However, it will be shown that for the present materials the effect of SDA on conductivity is very small and thus a further refinement leading to more complicated equations is not warranted.

The diffusion of an alloying element is calculated using the expression:

$$
D=D_{0} \exp \left(\frac{E_{D}}{k_{B} T}\right)
$$

where $E_{D}$ is the diffusion energy, $k_{B}$ is Boltzmann's constant, $D_{0}$ is a constant.

It is noted that although the present treatment is adequate for predicting conductivity, the solute depletion process is more complex than the simplified treatment presented here [8]. 


\subsection{Conductivity of the grains}

Conductivity of a dilute metallic alloy with precipitates is mainly governed by four factors: i) the conductivity of the pure metal (in our case the conductivity of pure $\mathrm{Al}, \sigma_{0}$ ), ii) the conductivity and volume fractions of the phases within the matrix, iii) the scattering of electrons by very small (nanometer sized) precipitates/zones [10], and iv) alloying atoms dissolved in the matrix phase. In the present model the factor iii will be neglected as we are dealing with overaged alloys in which precipitates will grow to relatively large sizes.

\subsubsection{Conductivity of the matrix phase - dissolved alloying elements}

Generally, the effect of dissolved alloying elements on the resistivity of a single phase is thought to be linear and additive (Matthiesen's rule) [25,26]:

$$
\frac{1}{\sigma_{M}(t)}=\rho_{M}(t)=\rho_{M, P}+\sum_{i=1}^{n} r_{i} x_{i}(t)
$$

where $\rho_{M}(t)$ is the resistivity of the matrix phase, $\rho_{M, P}$ is the resistivity of the pure metal, $\mathrm{n}$ is the number of alloying elements, $x_{i}$ is the concentration of alloying element $i$ in the matrix phase (which is time dependent due to precipitation that can occur), and $r_{i}$ are constants. Hence, for a 7xxx type alloy:

$$
\rho_{M}(t)=\rho_{A l}+r_{Z n} x_{Z n}(t)+r_{M g} x_{M g}(t)+r_{C u} x_{C u}(t)+r_{Z r} x_{Z r}(t)+r_{C r} x_{C r}(t)+r_{F e} x_{F e}(t)+r_{S i} x_{S i}(t)
$$

where $\rho_{A l}$ is the resistivity of pure Al. The procedure for calculating the values for $x_{i}$ is outlined below. In practice, diffusion of $\mathrm{Zr}, \mathrm{Cr}, \mathrm{Fe}$ and $\mathrm{Si}$ during ageing is too slow to cause any significant change in conductivity due to precipitation of these elements. Hence we can simplify the latter equation by taking:

$$
\rho_{M}(t)=\rho_{o}+r_{Z n} x_{Z n}(t)+r_{M g} x_{M g}(t)+r_{C u} x_{C u}(t)
$$

where $\rho_{o}$ is the resistivity of the alloy after precipitation of the precipitation hardening elements ( $\mathrm{Zn}, \mathrm{Mg}$ and $\mathrm{Cu}$ ) has been completed. This variable is related to the conductivity of the alloy after precipitation of the precipitation hardening elements, $\sigma_{o}$, as $\rho_{o}=1 / \sigma_{o}$.

\subsubsection{Undissolved Particles}

First, we calculate the amount of the alloying elements that do not dissolve during solution treatment. Alloying elements can remain undissolved because they are incorporated in phases that are stable at solution treatment temperatures. In 7xxx alloys this concerns mainly the $\mathrm{S}$ ( $\mathrm{Al}_{2} \mathrm{CuMg}$ ), $\mathrm{T}$ ( $\mathrm{Mg}_{3} \mathrm{Zn}_{3} \mathrm{Al}_{2}$ with some $\mathrm{Cu}$ dissolved in it), $\mathrm{Al}_{7} \mathrm{Cu}_{2} \mathrm{Fe}$ and $\mathrm{Mg}_{2} \mathrm{Si}$ phases $[27,31,32]$, where the presence of the latter two is caused by impurities Fe and Si. The 
amounts of each phase present can be calculated/predicted using thermodynamic models [33,34] or phase diagrams [35]. For the present work, $\mathrm{T}$ and $\mathrm{Mg}_{2} \mathrm{Si}$ are neglected because previous work $[16,36]$ has indicated that they are either not present or only present in limited amounts in commercial 7xxx alloys. To calculate the amounts of $\mathrm{S}$ and $\mathrm{Al}_{7} \mathrm{Cu}_{2} \mathrm{Fe}$, We will use simplified thermodynamic models outlined below.

The solubility of $\mathrm{Fe}$ in $\mathrm{Al}$ is not significantly influenced by $\mathrm{Cu}$ or $\mathrm{Mg}$ additions [28] and hence the amount of undissolved $\mathrm{Al}_{7} \mathrm{Cu}_{2} \mathrm{Fe}$ is simply calculated on the basis of the solubility of $\mathrm{Fe}$ in binary Al-Fe. For typical solution treatment temperatures of 7xxx alloys (460$485^{\circ} \mathrm{C}$ ) the solubility of $\mathrm{Fe}$ in $\mathrm{Al}, \mathrm{C}_{\mathrm{Fe}}\left(\mathrm{T}=\mathrm{T}_{\text {sol }}\right)$, is estimated at 0.0025 at $\%$ [28]. Consequently, the amount of $\mathrm{Al}_{7} \mathrm{Cu}_{2} \mathrm{Fe}$ present in the alloy after solution treatment is given by:

$$
y_{A l 7 \mathrm{Cu} 2 \mathrm{Fe}}=10\left(x_{\mathrm{Fe}}^{g}-c_{F e}\left(T=T_{s o l}\right)\right)
$$

where $x_{\mathrm{Fe}}^{g}$ is the gross Fe content of the alloy (the factor 10 appears because in $\mathrm{Al}_{7} \mathrm{Cu}_{2} \mathrm{Fe}$ there are 10 atoms in the phase per atom of Fe).

The amount of S phase is obtained using a regular solution model [27,37,38], which has been shown to be a good approximation of for the solvus of S phase in Al-Zn-Mg-Cu alloys [27]. In this model the solvus related to an intermetallic phase $M_{m} A_{a} B_{b} C_{c}$ ( $\mathrm{M}$ is the main constituent of the alloy, and A, B, C are the alloying elements) is given by:

$$
\left(c_{A}\right)^{a}\left(c_{B}\right)^{b}\left(c_{C}\right)^{c}=c_{0} \exp \left[\frac{-\Delta H_{\text {sol }}}{k_{B} T}\right]
$$

where $\Delta H_{\text {sol }}$ is the enthalpy of formation per $M_{m} A_{a} B_{b} C_{c}$ unit, $k_{B}$ is Boltzmann's constant and $c_{0}$ is a constant. If appropriate values for $\Delta H_{\text {sol }}, c_{0}, a, b, c$ can be derived from available solubility data, a phase diagram can be constructed. For the $\mathrm{S}$ phase, $\Delta H_{\text {sol }}^{s}$ in ternary alloys has been determined before [37,38], and by combining solvus data at $460^{\circ} \mathrm{C}$ [39] with $\Delta H_{\text {sol }}^{s}$, the $\mathrm{S}$ solvus as a function of the temperature can be estimated. This procedure for calculating the amount of undissolved S phase, $y_{s}$ is outlined in detail in Ref. [12].

After calculation of $y_{s}$ and $y_{\mathrm{Al}_{7} \mathrm{Cu}_{2} \mathrm{Fe}}$ the fractions of the elements dissolved in the Al-rich phase after solution treatment can be obtained from:

$$
\begin{aligned}
& x_{\mathrm{Cu}}(t=0)=\frac{x_{\mathrm{Cu}}^{g}-\frac{2}{10} y_{\mathrm{Al}_{7} \mathrm{Cu} \mathrm{Fe}}-\frac{1}{4} y_{S}}{1-y_{\mathrm{Al}_{7} \mathrm{Cu} u_{2} \mathrm{Fe}}-y_{S}} \\
& x_{\mathrm{Mg}}(t=0)=\frac{x_{\mathrm{Mg}}^{g}-\frac{1}{4} y_{S}}{1-y_{\mathrm{Al} l_{7} \mathrm{Cu}_{2} \mathrm{Fe}}-y_{S}} \\
& x_{\mathrm{Fe}}(t=0)=\frac{x_{\mathrm{Fe}}^{g}-\frac{1}{10} y_{\mathrm{Al}_{7} \mathrm{Cu} \mathrm{Fe}}}{1-y_{\mathrm{Al}_{7} \mathrm{Cu}_{2} \mathrm{Fe}}-y_{S}}
\end{aligned}
$$




$$
x_{Z n}(t=0)=\frac{x_{Z n}^{g}}{1-y_{A l_{7} C u_{2} F e}-y_{S}}
$$

and similar for Si.

The $\mathrm{S}$ and $\mathrm{Al}_{7} \mathrm{Cu}_{2} \mathrm{Fe}$ particles will have a conductivity which differs from the matrix and will thus influence the conductivity of the alloy. This effect is taken account of by employing the Rayleigh-Maxwell equation for dispersed conducting particles in a conducting matrix [40,41]:

$$
\rho_{\text {comp }}=\rho_{M} \frac{1+2 V_{p}\left(\frac{1-\rho_{M} / \rho_{p}}{2 \rho_{M} / \rho_{p}+1}\right)}{1-V_{p}\left(\frac{1-\rho_{M} / \rho_{p}}{2 \rho_{M} / \rho_{p}+1}\right)}
$$

where $\rho_{\text {comp }}$ is the resistivity of the matrix with particles in it (i.e. the composite), $\rho_{M}$ is the resistivity of the matrix phase, $\rho_{p}$ is the resistivity of the particles and $V_{p}$ is the volume fraction of particles. The volume fraction of the particles can be calculated from their densities, i.e. (for $\mathrm{S}$ phase):

$$
V_{S}=y_{S} \frac{M_{M}}{M_{S}}
$$

where $M_{M}$ and $M_{S}$ are the atomic densities (e.g. in atoms $/ \mathrm{m}^{3}$ ) of the matrix and the $\mathrm{S}$ phase, respectively. Due to lack of data we approximate $\rho_{S} \approx \rho_{A l 7 C u 2 F e} \approx \rho_{A l}$ and $V_{S} \approx y_{S}$. It is noted that for the 7xxx alloys studied, $y_{S}+y_{A l 7 C u 2 F e}<0.03$ and, hence, these undissolved intermetallic phases have a limited direct influence on the conductivity. The present approximations for $\rho_{S}$ and $\rho_{A l 7 C u 2 F e}$ will thus not significantly influence accuracy.

\subsubsection{Precipitation and coarsening}

Having determined the concentrations of the different elements dissolved at the start of the ageing process, $x_{i}(t=0)$, the next step is the determination of the concentrations of the elements after a very long ageing treatment, when (meta-)stable equilibrium is reached, $x_{i}(t=\infty)$. In the present model, we will assume that in good approximation the composition of the precipitating phase is fixed, and hence it follows:

$$
x_{i}(t)=x_{i}(t=0)-\alpha(t, T)\left[x_{i}(t=0)-x_{i}(t=\infty)\right]
$$


where $\alpha(t, T)$ is the fraction transformed in the course of the precipitation reaction. In addition, we will approximate the precipitation by assuming that the precipitation in the grain is exclusively $\eta^{\prime}$ phase. Some controversy exists concerning the composition of the $\eta^{\prime}$ phase, with atom-probe data suggesting a $\mathrm{Zn:Mg}$ ratio of about 1.2-1.5 with very low $\mathrm{Cu}$ content $(\mathrm{Cu}: \mathrm{Zn}=0.1)[42,43,44]$, and small angle X-ray scattering (SAXS) a suggesting a much higher $\mathrm{Zn}$ content [44], closer to the $\mathrm{Zn:Mg}$ ratio of 2.5 in the suggested structure of $\eta^{\prime}$ phase based on an analysis of selected area diffraction data [45]. We will assume that the $\mathrm{Zn:Mg}$ ratio can be approximated to equal 2, and that in good approximation $\eta^{\prime}$ does not contain $\mathrm{Cu}$. Thus after completion of precipitation reaction the $\mathrm{Cu}$ content is equal to the initial $\mathrm{Cu}$ content, i.e. $x_{C u}(t=\infty)=x_{C u}(t=0)$. According to the regular solution model, the solvus of $\eta^{\prime}$ for $\eta^{\prime}$ particles that are large (i.e. in the absence of any capillary effects [11]) can then be approximated as:

$$
\left(c_{Z n}\right)^{2} \times\left(c_{M g}\right)=c_{0} \exp \left(\frac{-\Delta H_{s o l}^{\eta^{\prime}}}{k_{B} T}\right)
$$

where $c_{Z n}$ and $c_{M g}$ are equilibrium concentrations of alloying elements $\mathrm{Zn}$ and $\mathrm{Mg}, \Delta H_{s o l}^{\eta^{\prime}}$ is the solution enthalpy of $\eta^{\prime}$. In a simple approximation, one might chose to assume that the final $\mathrm{Zn}$ content is much less than the initial one and that $\mathrm{Zn}$ is nearly consumed after completion of precipitation reaction, i.e. $x_{Z n}(t=\infty)=0$, i.e.:

$$
x_{M g}(t=\infty)=x_{M g}(t=0)-2 x_{Z n}(t=0)
$$

This type of simplified approach was explored in an earlier, simpler version of a conductivity model, which led to an accurate description of the conductivity data [46]. In the present, more detailed model, we will take account of coarsening of precipitates and the effect on metastable solubility through the capillary effect (see e.g. [11]). To describe particle growth during coarsening we will approximate the precipitates as being spherical and adopt the Lifshitz-Slyozov-Wagner (LSW) theory (see e.g. Refs. [11,47] and references therein), which predicts that the average particle size increases as:

$$
r^{3}-r_{o}^{3}=K\left(t-t_{o}\right)
$$

where $r$ is the average particle radius, $r_{o}$ is the average particle radius at the start of the coarsening stage, $t_{o}$, and $K$ is a temperature dependent factor (see [11]). The capillary effect that is related to this coarsening will affect the metastable solvus of $\eta^{\prime}$ particles, such that the metastable solvus for small particles that are coarsening is given by:

$$
\left(c_{Z n}\right)^{2} \times\left(c_{M g}\right)=c_{0} \exp \left(\frac{-\Delta H_{s o l}^{\eta^{\prime}}+2 \Omega \gamma / r}{k_{B} T}\right)
$$


where $\gamma$ is the interfacial energy between precipitate and matrix, $\Omega$ is the atomic volume of the particle.

In modelling results presented in this paper, the metastable solvus of $\eta^{\prime}$ was calculated using the regular solution model with the parameters approximated as $\Delta H_{\text {sol }}^{\eta^{\prime}}=26.6 \mathrm{~kJ} / \mathrm{mole}, \mathrm{c}_{\mathrm{o}}=$ 3.85, and $\mathrm{Zn}: \mathrm{Mg}$ ratio of the precipitates fixed at 2. This $\mathrm{Zn}: \mathrm{Mg}$ ratio was initially chosen because it seems to be a reasonable average of conflicting data on the composition of the precipitates (see section 3.2.3) and this ratio is also consistent with the analysis of (limited) solubility data by Brown and Wiley [26]. In addition, further analysis (not presented) by varying the $\mathrm{Zn:Mg}$ ratio of the precipitates between 1.2 and 2.5 showed very limited changes in accuracy of the model. $\Delta H_{\text {sol }}^{\eta}$ was determined by fitting the above equation to equilibrium solubility data obtained from thermodynamic modelling [34], i.e. it is being assumed that the enthalpy of formation of $\eta^{\prime}$ is similar to that of the equilibrium phase $\eta^{\prime}$. Finally $c_{o}$ is estimated from solubility data in [26].

The temperature dependent fraction $\alpha(t, T)$ can be approximated using the Starink-Zahra expression $[48,49,50]$ :

$$
\alpha(t, T)=1-\left\{\frac{[k(T) t]^{n}}{\eta_{i}}+1\right\}^{-\eta_{i}}
$$

where $\eta_{i}$ is the impingement parameter, $k(T)$ is a temperature dependent factor, $\mathrm{n}$ is a kinetic exponent similar to the Avrami exponent [48]. $k(T)$ can be expressed by an Arrhenius relation [14]:

$$
k(T)=k_{0} \exp \left(-\frac{E_{a}}{k_{B} T}\right)
$$

where $E_{a}$ is the activation energy which has contributions from both the nucleation and growth [14], $k_{0}$ is a constant. Owing to the amounts transformed being temperature dependent (through the factor $k(T)$ ), the overall conductivity changes are affected by the temperature. The latter two equations can be used to calculate fractions transformed for non-isothermal ageing, i.e. through integration. This will be used in the present model to account for the linear heating to the ageing temperature, by taking $E_{a}=155 \mathrm{~kJ} / \mathrm{mol}$ [11]. After calculation of the concentrations of individual alloying elements, the conductivity of the grains can be calculated by equation (12).

\section{Results}

\subsection{Microstructure}

Microstructural analysis was carried out for selected alloys out of two groups of alloys. Grain structure, intermetallic particles, precipitates as well as precipitation evolution were studied using various techniques. Fig. 3 shows optical micrographs revealing intermetallic particles and grain structures of the alloys. Fig. 4 shows high angle and low angle (sub-)grain 
boundaries as assessed by EBSD. The latter figure reveals that all samples contain large $(>40 \mu \mathrm{m})$ elongated grains bounded predominantly by high angle grain boundaries that have no internal boundaries. These grains are thought to be recrystallised grains. Other regions bounded by high angle grain boundaries have a high density of internal low angle grain boundaries, which sometimes outline (sub-) grains with sizes less than $20 \mu \mathrm{m}$. Due to the accuracy limit of orientation determination in EBSD and the lower limit imposed on identifying grain boundaries in the EBSD software, not all subgrain boundaries are revealed in Fig. 4, however TEM confirmed the presence of a subgrain structure with subgrains of about $4 \mu \mathrm{m}$ diameter. Fig. 4 shows that the Zr containing alloys are about $25 \%$ recrystallised, whilst the Cr-containing alloy is about $65 \%$ recrystallised.

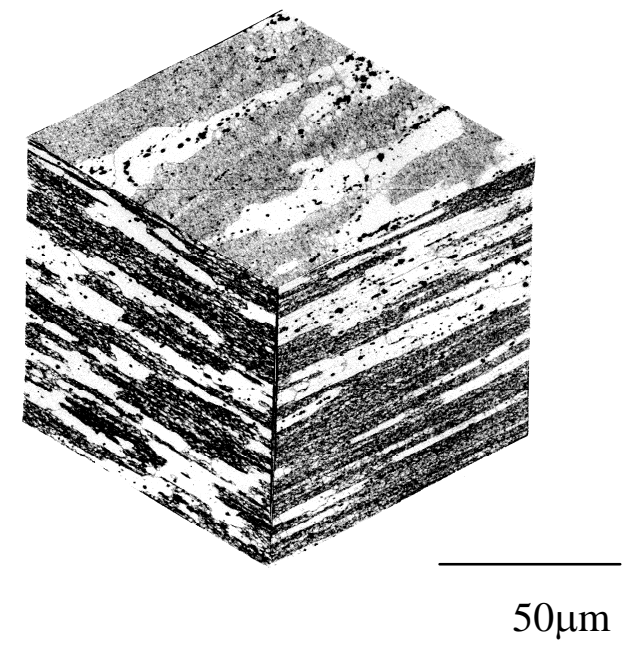

a)

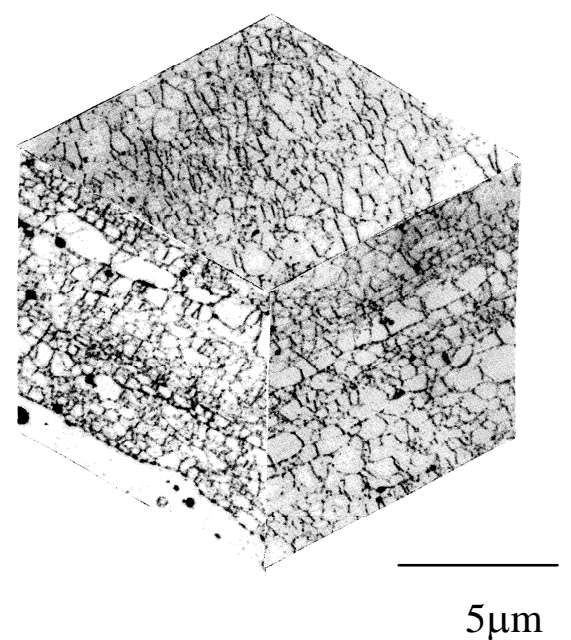

b)

Fig. 3 Three dimensional grain structures of the overaged Zr-containing Al-6.7Zn-2.9Mg1.9Cu (wt\%) alloy: a) low magnification; b) high magnification

SEM and EDS studies on the Zr containing alloys concluded that the intermetallic particles are mostly $\mathrm{S}$ phase and $\mathrm{Al}_{7} \mathrm{Cu}_{2} \mathrm{Fe}$ phase, whilst a trace of $\mathrm{T}$ phase is present in only one alloy which contains high $\mathrm{Mg}$ content $(\mathrm{Mg}>2.9 \mathrm{wt} \%)$ [27]. The Cr-containing alloys contain $\mathrm{S}$ phase and $\mathrm{Al}_{7} \mathrm{Cu}_{2} \mathrm{Fe}$ phase (Fig. 5).

DSC experiments reveal the endothermic peak due to dissolution of $\eta^{\prime}$ starting at about $160^{\circ} \mathrm{C}$ and continuing up to about $230^{\circ} \mathrm{C}$ for alloys aged for $2 \mathrm{~h}$ and up to $260^{\circ} \mathrm{C}$ for alloys aged for $16 \mathrm{~h}$ (Fig. 7 and [22]). The peak is at about 200-220 ${ }^{\circ} \mathrm{C}$. Between about 290 and $470^{\circ} \mathrm{C}$ all curves are dominated by an endothermic effect due to $\eta$ dissolution. Whilst underaged 7xxx alloys show a strong exothermic peak due to $\eta^{\prime}$ and $\eta$ formation between about 200 and $270^{\circ} \mathrm{C}$ [51], the DSC curves of the present peak aged and overaged alloys only show a remnant of this effect between about 220 and $290^{\circ} \mathrm{C}$, in the form of a relatively small exothermic effect superimposed on a dominant endothermic effect. Thus the DSC curves in Fig. 7 indicate that during the DSC run some $\eta$ formation occurs in the alloy aged for $2 \mathrm{~h}$ and that the amount of $\eta$ formation during the DSC decreases on further ageing up to $16 \mathrm{~h}$. 

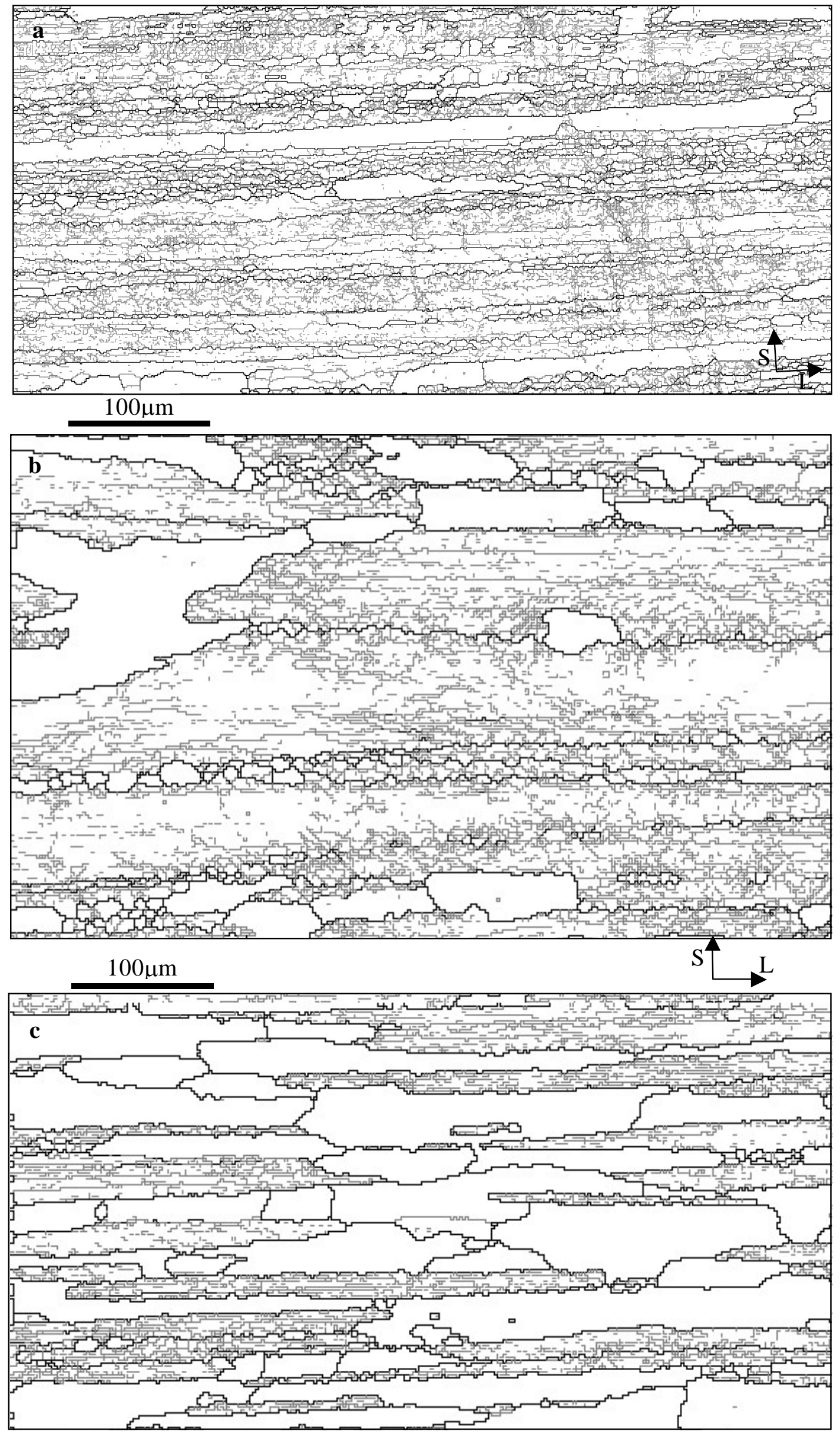


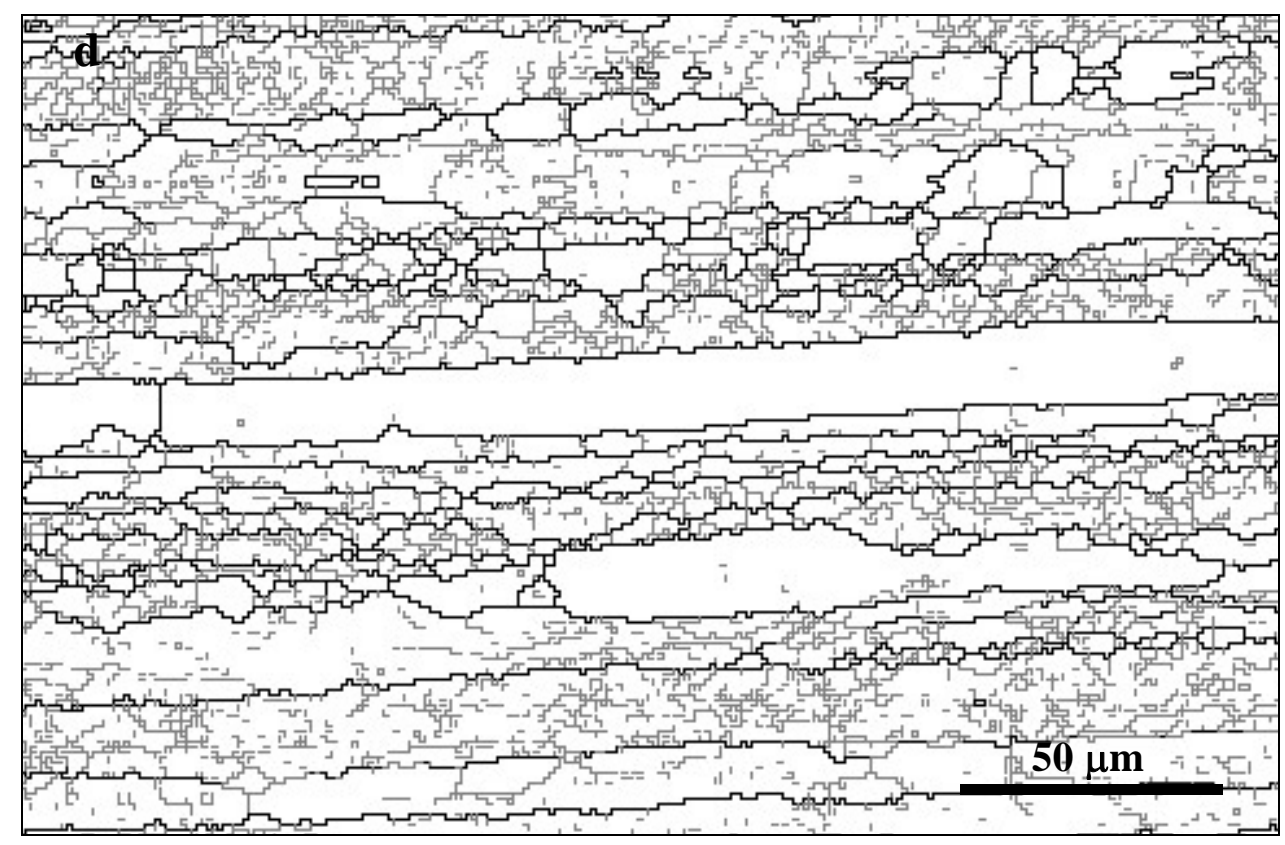

Fig. 4 EBSD data showing the grain boundaries in the Al-5.9Zn-2.3Mg-1.8Cu-0.12Zr (a), Al-6.1Zn-2.3Mg-2.6Cu-0.12Zr (b), and the Al-6.2Zn-3.0Mg-2.0Cu-0.2Cr alloys (c). A magnified image of the grain boundaries in alloy $\mathrm{Al}-5.9 \mathrm{Zn}-2.3 \mathrm{Mg}-1.8 \mathrm{Cu}-0.12 \mathrm{Zr}$ is presented in (d). Dark lines represent grain boundaries with grain rotation $>12^{\circ}$ and grey lines represent grain boundaries with grain rotation between 2 and $12^{\circ}$. EBSD pattern collection stepsize is $1 \mu \mathrm{m}(\mathrm{a}, \mathrm{d})$ or $2 \mu \mathrm{m}(\mathrm{b}, \mathrm{c})$.

The fact that the exothermic $\eta$ formation is small, indicates that a substantial amount of $\eta$ phase is present in all the samples, whilst the dissolution peak of $\eta^{\prime}$ at about $200-220^{\circ} \mathrm{C}$ indicates that alloys also contain $\eta^{\prime}$. Especially for alloys aged $2 \mathrm{~h}$ and $4 \mathrm{~h}$ the distinct $\eta^{\prime}$ dissolution effect indicates that substantial $\eta^{\prime}$ is present. For samples aged 8 and $16 \mathrm{~h}$ at $172^{\circ} \mathrm{C}$ the remnant of the exothermic effect superimposed on the endothermic effect decreases very significantly, which indicates that at that stage $\eta$ phase precipitation at $172^{\circ} \mathrm{C}$ is nearing completion. Hence, during ageing at $172^{\circ} \mathrm{C}$ a change from the precipitation to the coarsening stage is occurring at about $10 \mathrm{~h}$ ageing. The DSC curves also show incipient melting reactions at about 480 and $490^{\circ} \mathrm{C}$. This is due to intermetallic phases present in the alloys and these phases can have an important influence on the damage tolerance of the alloys. These reactions are studied in detail in an earlier paper [27].

TEM investigation of selected $\mathrm{Cr}$ containing and $\mathrm{Zr}$ containing alloys revealed the fine microstructures of our 7xxx alloys: precipitates in the matrix, grain (or subgrain) boundaries and PFZs, a typical TEM micrograph with selected area diffraction pattern (SADP) of an alloy aged for $16 \mathrm{~h}$ at $172{ }^{\circ} \mathrm{C}$ is given in Fig. 6. The origin of the fainter spots and streaks appearing in a cross-like pattern in the SADP (Fig. 6b) remain controversial according to available literature. For instance, Park and Ardell [52] and Deschamps and Brechet [53] regarded this to be due to $\eta$, whereas Stiller et al [43] attributed this to a combination of $\eta$ 
and $\eta^{\prime}$ phase. Our analysis of our DSC data (as presented above and in [22]) suggests that this diffraction feature is mainly due to the $\eta$ phase.

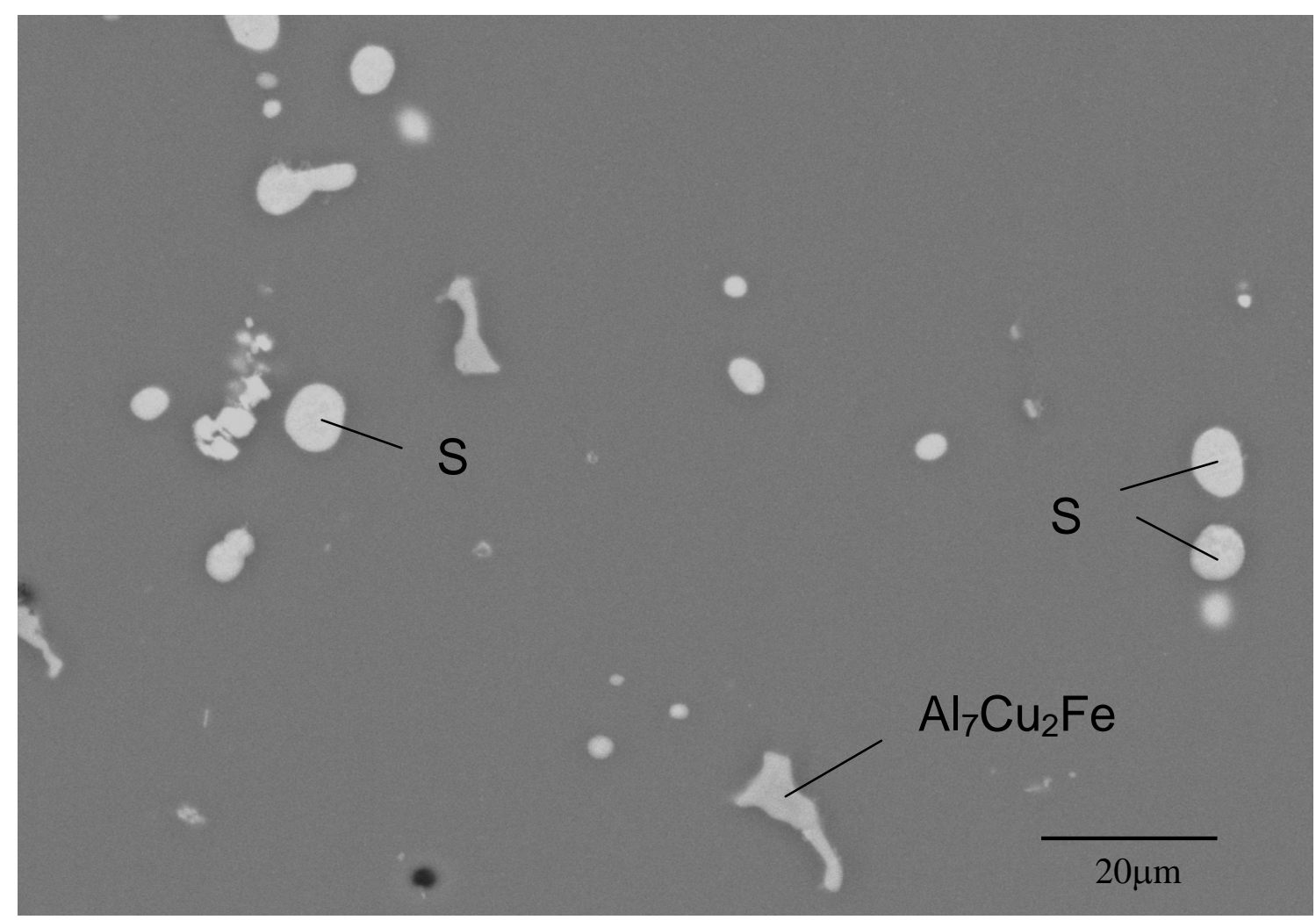

Fig. 5 SEM micrograph of the Cr-containing Al-6.2Zn-3.0Mg-2.0Cu (wt\%) alloy, showing the main particles: $\mathrm{S}$ and $\mathrm{Al}_{7} \mathrm{Cu}_{2} \mathrm{Fe}$ phases

\subsection{Conductivity Modelling}

The conductivity model described in Section 3 was used to fit the conductivity data of the nine $\mathrm{Zr}$-containing alloys and the five Cr-containing alloys using a procedure of least squares, i.e. parameters were optimised such that the sum of the squares of the differences between measured conductivity and predicted conductivity is smallest. The resulting accuracy is reported in terms of the root mean square error (RMSE). To fully explore the capability of the present model a range of fits with different combinations of fixed and fitted parameters were tested. Throughout all the analysis, between 2 to 5 parameters (the $\sigma_{0}, k$ and $r$ coefficients) are fitted to obtain the best modelling accuracy on the data, i.e. the lowest RMSE on the training data. The true accuracy of the model in terms of its capability to predict "unseen" data was tested for selected cases using a rigorous procedure generally used in AN modelling [12,13]. In this procedure, data is repeatedly split into two groups, training data and test (or unseen) data, the training data is used to identify the modelling parameters and the test/unseen data is used to validate the model. In our modelling approach, $\sim 80 \%$ of the total data was randomly selected to train the model, whilst the remaining $\sim 20 \%$ of the 
data was used to test the model, and this training-testing procedure was repeated at least 10 times. This procedure showed that independent of the data set ( $\mathrm{Zr}$ or Cr containing alloys) and independent of the choice of $n$, test RMSEs are up to about $10 \%$ higher than training RMSEs. This difference is quite small, which means that means that the models are not overfitting and that in all cases the presented training RMSE is a good measure of the test RMSE, i.e. of the capability to predict "unseen" data.

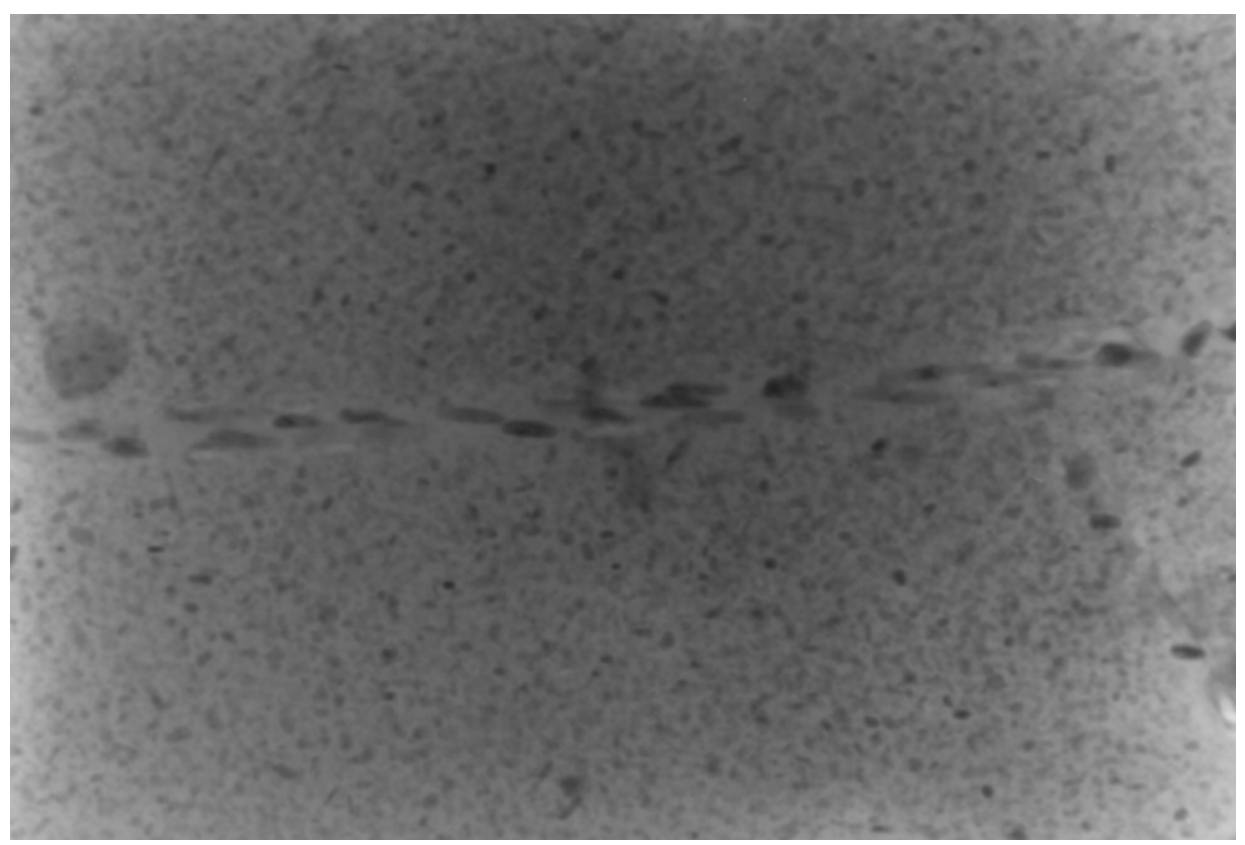

a)

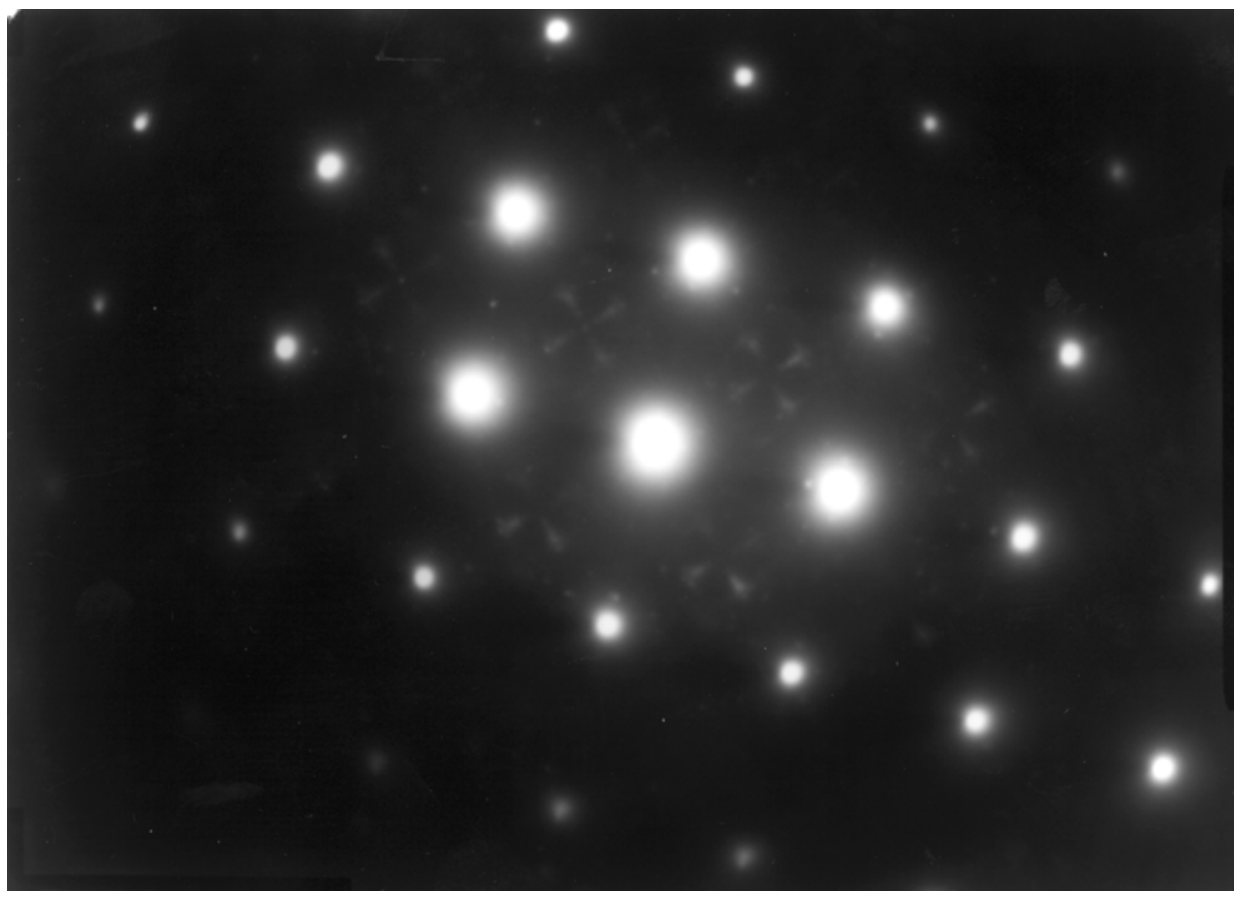

b)

Fig. 6 a) TEM micrograph of the Zr-containing Al-6.7Zn-2.9Mg-1.9Cu (wt\%) alloy aged for $16 \mathrm{~h}$ at $172^{\circ} \mathrm{C}$, showing subgrain boundaries and narrow PFZs adjacent to the boundaries (bright-field, $B=[100])$. b) Selected area diffraction pattern from this sample $(B=[100])$ 


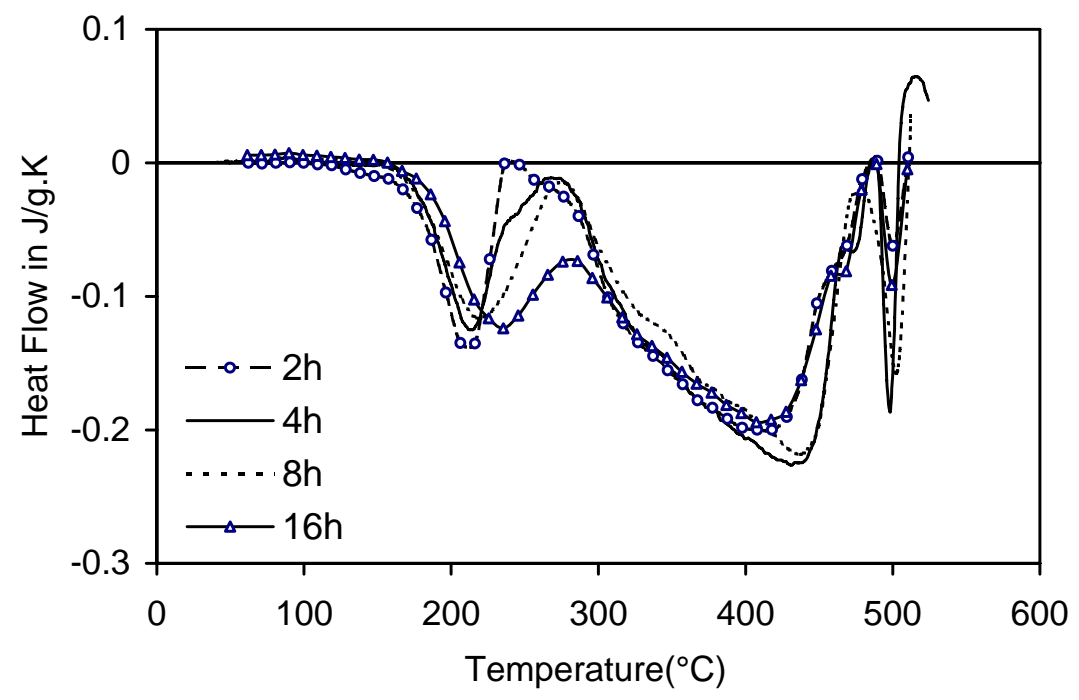

Fig. 7 DSC curves of the Al-5.9Zn-2.3Mg-1.8Cu-0.12Zr (wt\%) alloy aged at $172^{\circ} \mathrm{C}$ for 2, 4, 8 and $16 \mathrm{~h}$. Heating rate $10^{\circ} \mathrm{C} / \mathrm{min}$.

An illustration of the results obtained by this train and test procedure is provided in Fig. 8. In the subsequent paragraphs we will describe how a range of parameters were fixed by using microstructural data and knowledge about the metallurgy and reaction kinetics of the alloys. From the TEM experiments it was observed that in alloys aged for 16 hours at $172{ }^{\circ} \mathrm{C}$ the precipitate free zone around the grain boundary extends about $20 \mathrm{~nm}$ into the grain, and it is expected that the solute depleted area is of similar size, i.e. $d_{S D A} \approx 20 \mathrm{~nm}$. An SDA of this size would increase conductivity by about $0.1 \%$ IACS, i.e. the influence of SDA on the conductivity is very small. Small deviations in the $d_{S D A}$ will not significantly influence the overall accuracy of the model, as other fitted parameters will compensate for any minor loss of accuracy. Hence, we will estimate $d_{S D A}(\mathrm{t}=16 \mathrm{~h})=20 \mathrm{~nm}$. Assuming that $\mathrm{Mg}$ diffusion is the rate limiting process in the growth of the SDA, the activation energy for the process is taken as the activation energy for $\mathrm{Mg}$ diffusion $\left(E_{A}=117 \mathrm{~kJ} / \mathrm{mole}\right.$, see [28]). Using these approximations the size of the SDA was calculated for all ageing times and temperatures, whilst $d_{T}$ was taken as $4 \mu \mathrm{m}$.

As no data is available on the interfacial energy between precipitate and matrix, $\gamma$, we elected to use the following procedure to estimate the capillary effect on conductivity. Throughout our assessment we will make the simplifying assumption that the capillarity effect of the ellipsoidal precipitates in our alloys can be approximated as the capillarity of spherical precipitates, with sizes estimated from the average dimension of the precipitates. The size of precipitates in our alloys was estimated from the present TEM data and other data appearing in the literature. This assessment indicates that at the peak-aged condition, which a separate assessment for our alloys showed to correspond to about $2 \mathrm{~h}$ ageing at $172{ }^{\circ} \mathrm{C}$, the precipitate radius is about $2 \mathrm{~nm}$ [42,54]. We will assume coarsening effectively starts after attaining peak strength, and hence we will choose $r_{o}=2 \mathrm{~nm}$ and $t_{o}=2 \mathrm{~h}$. Our TEM work (see previous section) indicates that after $16 \mathrm{~h}$ ageing at $172^{\circ} \mathrm{C}$ precipitate radius has increased to about 5 
$\mathrm{nm}$, and this finding is consistent with APFIM work on similar alloys [42]. From this the coarsening rate, $K$, is determined as $3.9 \mathrm{~nm}^{3} / \mathrm{h}$.

In defining the value of the Avrami exponent, $n$, it was considered that for diffusioncontrolled reactions $n$ needs to be an integral or half integral value between $1 / 2$ and $2 \frac{1}{2}$ $[48,49,14]$. It was found that for both $\mathrm{Zr}$ and $\mathrm{Cr}$ containing $7 \mathrm{xxx}$ alloys good fits could be obtained with $n$ equalling 2 or $2 \frac{1}{2}$, and for clarity we will present results for $n=2 \frac{1}{2}$ only. Separate assessment of the influence of the impingement parameter, $\eta_{i}$, showed that best fits always led to $\eta_{i}=\infty$, which corresponds to JMAK kinetics (see Ref $[48,49]$ ). Hence, throughout we have taken $\eta_{i}$ to be infinitely large (in practice this means setting $\eta_{i}$ at a fixed value in excess of 100).

The modelling parameters and training RMSEs obtained for several fits to 9 Zr-containing alloys and $5 \mathrm{Cr}$-containing alloys are presented in Table 2. The prediction scatter plots of conductivity for $9 \mathrm{Zr}$-containing alloys aged at $172^{\circ} \mathrm{C}$ is shown in Fig. 9. The results indicate that the model fits well to the measured conductivity (training data) with root mean square error (RMSE) about 0.4\%IACS for both datasets. The predicted conductivity of four $\mathrm{Zr}$ containing alloys vs. ageing time is shown in Fig. 10. This figure reveals that at the early stage of ageing (ageing time less than 10h) the conductivity increases quite fast, whilst, as ageing proceeds further, conductivity increases at a very much reduced rate. In Fig. 11 the predicted $\mathrm{Zn}$ and $\mathrm{Mg}$ concentrations in the Al-rich phase have been presented for one of the alloys in Fig. 10. In the same figure also the predicted radius of the precipitates is presented. A comparison of the two figures shows that the conductivity changes are related to the changes in solute content of the Al-rich phase. This is because the conductivity of the alloy is mainly determined by the conductivity of the grains, which in turn is dominated by the effect of dissolved alloying elements through Eq. 11.

Table 2 Modelling parameters of the 5 Cr-containing alloys (20 datapoints), compared with the $9 \mathrm{Zr}$-containing alloys (36 data points). Italics indicate parameters fitted, underlined data indicates parameters that were fixed throughout, normal font indicates parameters that were fitted for the Zr-containing alloys and subsequently used for the Cr containing alloys.

\begin{tabular}{c|cc}
\hline Parameters & Zr-containing alloys & Cr-containing alloys \\
\hline$\sigma_{0}(\% \mathrm{IACS})$ & 57.3 & 52.6 \\
\left.${\mathrm{k}\left(\mathrm{h}^{-1}\right)}^{-1}\right)$ & 0.16 & 0.14 \\
$r_{Z n}\left(\% \mathrm{IACS}^{-1}\right)$ & -0.02 & -0.02 \\
$r_{M g}\left(\% \mathrm{IACS}^{-1}\right)$ & -0.36 & -0.36 \\
$r_{C u}\left(\% \mathrm{IACS}^{-1}\right)$ & -0.09 & -0.09 \\
$\gamma\left(\mathrm{kJ}_{\mathrm{nm}}{ }^{2}\right)$ & 4.2 & 4.2 \\
$n$ & $\underline{2.5}$ & $\underline{2.5}$ \\
Zn:Mg & $\underline{2}$ & $\underline{2}$ \\
RMSE(training) & 0.44 & 0.41 \\
\hline
\end{tabular}




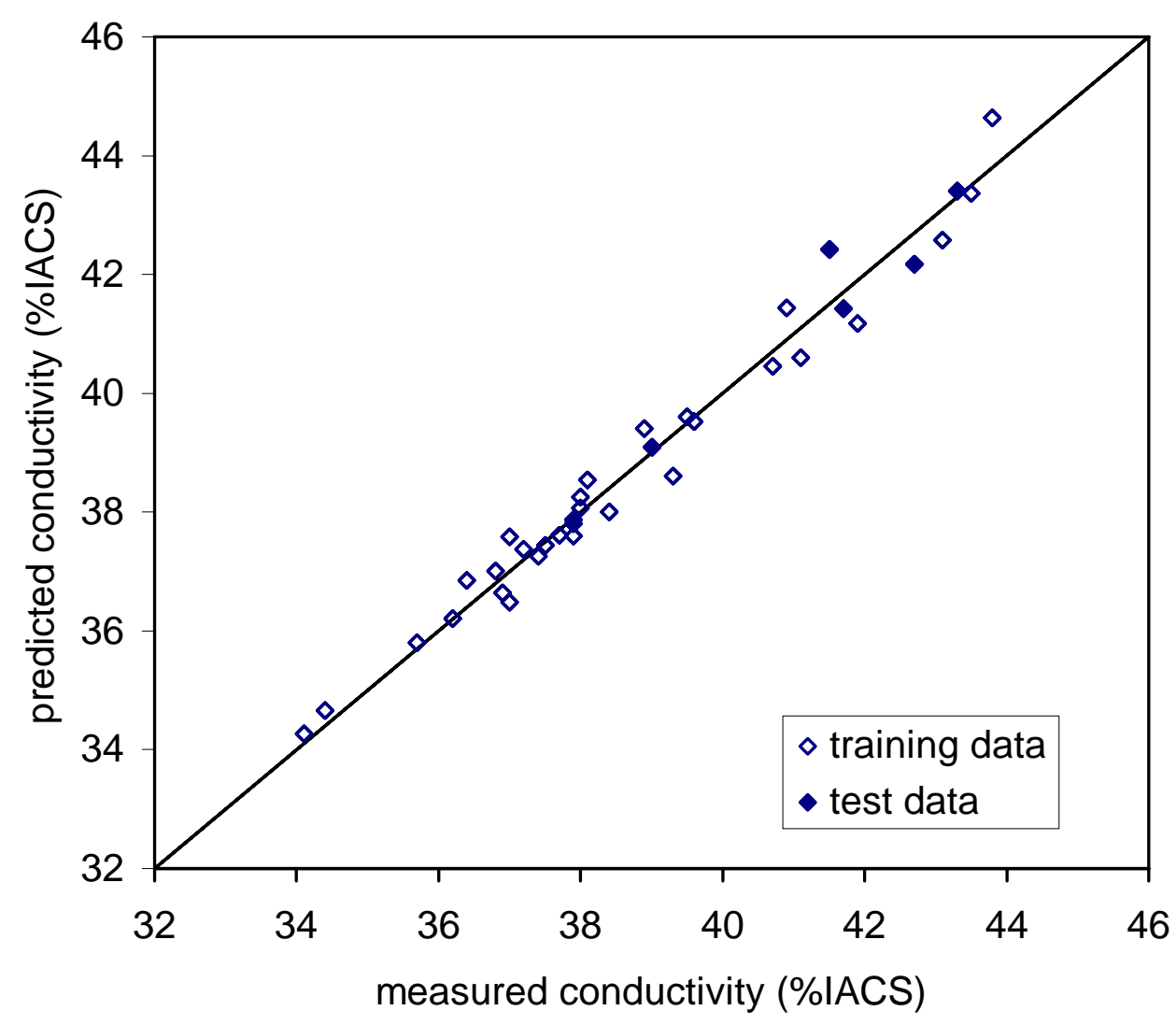

Fig. 8 A typical scatter plot of $9 \mathrm{Zr}$-containing alloys aged at $172^{\circ} \mathrm{C}$ for various ageing times (36 data points) including test and training data

Due to the fact that the model is based on analytical expressions it can be used to analyse a multitude of relations between composition, processing parameters (ageing time, ageing temperature, solution treatment temperature) and final property. As an example, Fig. 12 presents the ageing time needed to achieve a conductivity of 39.5\%IACS (the minimum specification for alloy 7050 in T76 tempers) for alloys containing 6.2wt\% Zn (a typical Zn content for alloy 7050) as a function of $\mathrm{Mg}$ and $\mathrm{Cu}$ content. This figure defines the minimum ageing time required to achieve acceptable conductivity of this important commercial alloy. It again highlights the importance of $\mathrm{Mg}$ content in defining conductivity and shows that achieving the minimum required conductivity should generally not be problem for this $\mathrm{Zr}$ containing alloy. A similar analysis for $\mathrm{Cr}$ containing alloys highlights that achieving minimum conductivity for 7x75 type alloys depends critically on composition and heat treatment. 


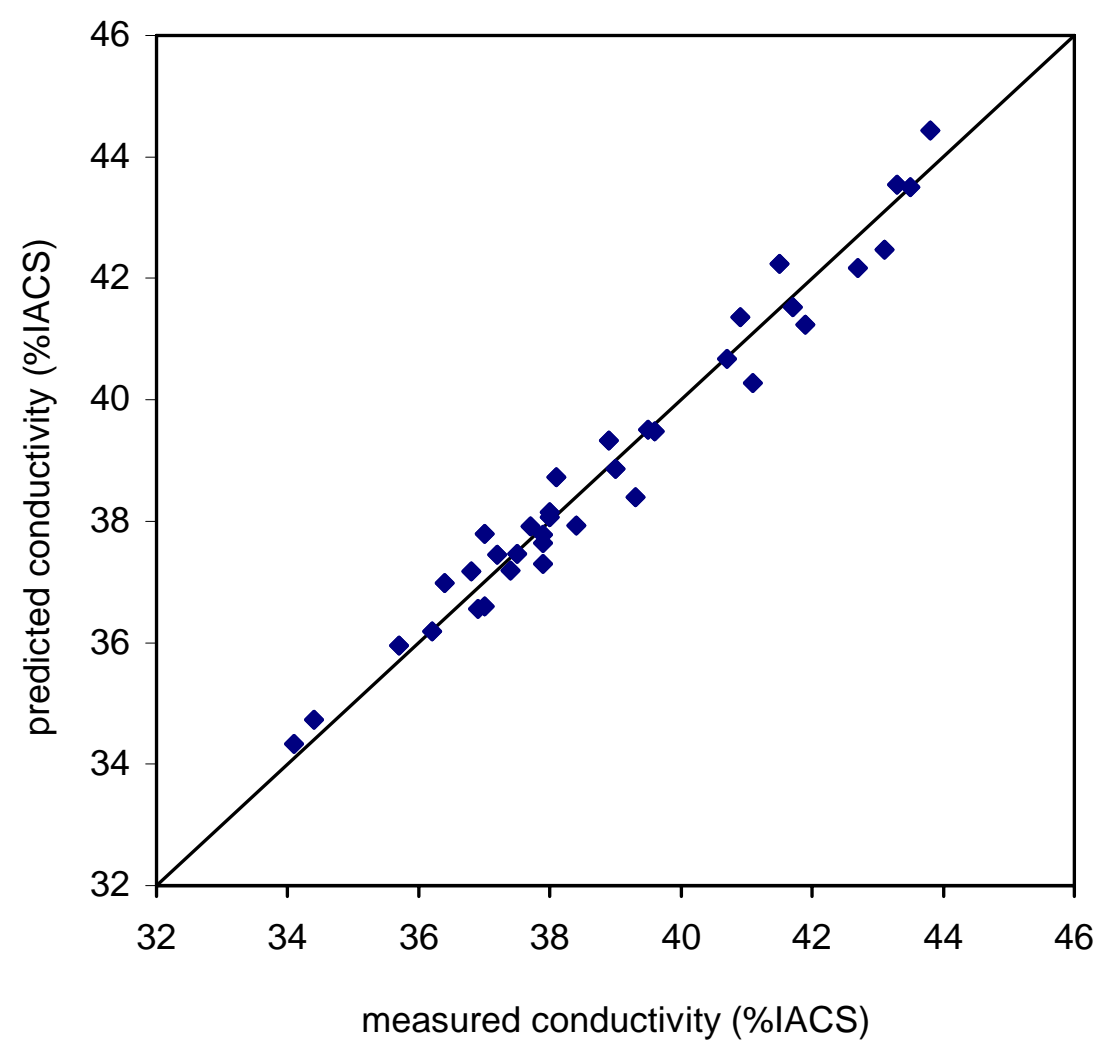

Fig. 9 Prediction scatter plots of $9 \mathrm{Zr}$-containing alloys aged at $172^{\circ} \mathrm{C}$ for various ageing times (36 data points).

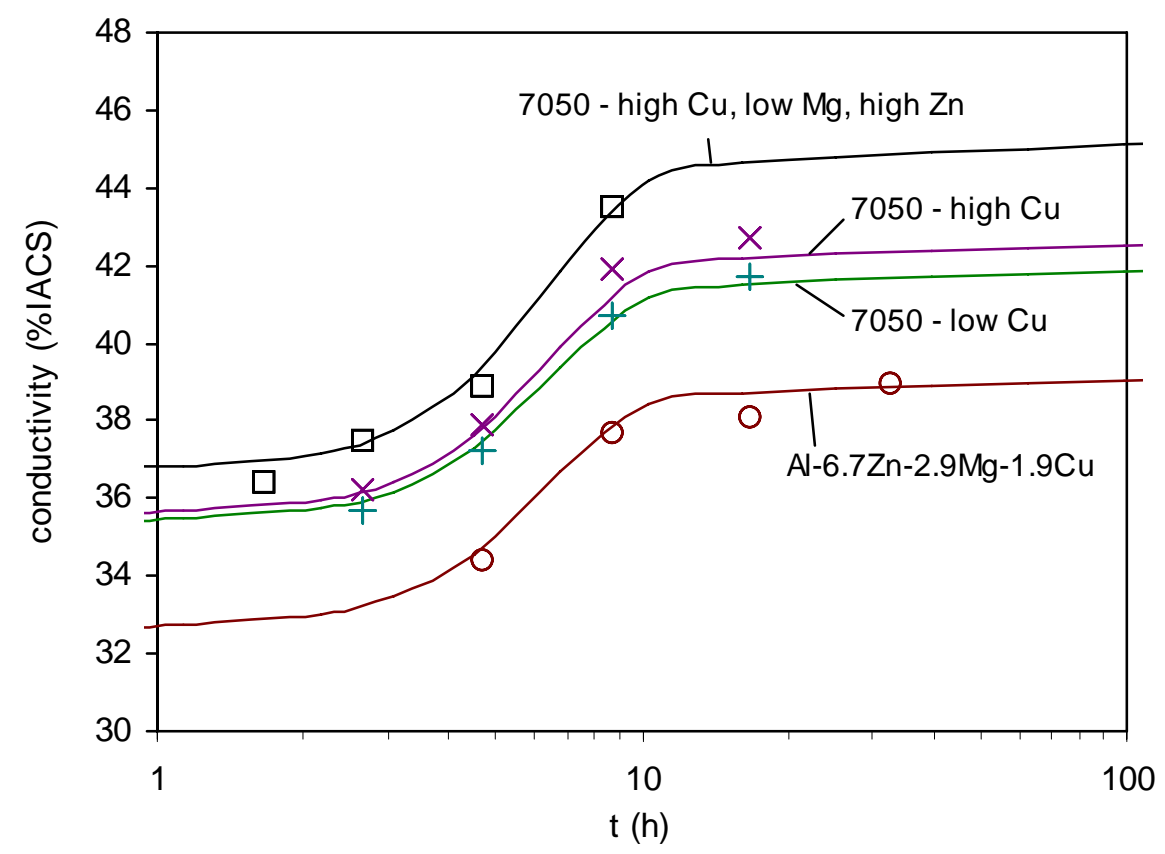

Fig. 10 Conductivity vs. ageing time graphs of four Zr-containing alloys aged at $172{ }^{\circ} \mathrm{C}$. Three alloys have compositions close to the limits of 7050 specifications, one alloy has a $\mathrm{Mg}$ content that is $0.3 \mathrm{wt} \%$ higher than 7050 specification. The points represent measured data, curves represent model predictions. 


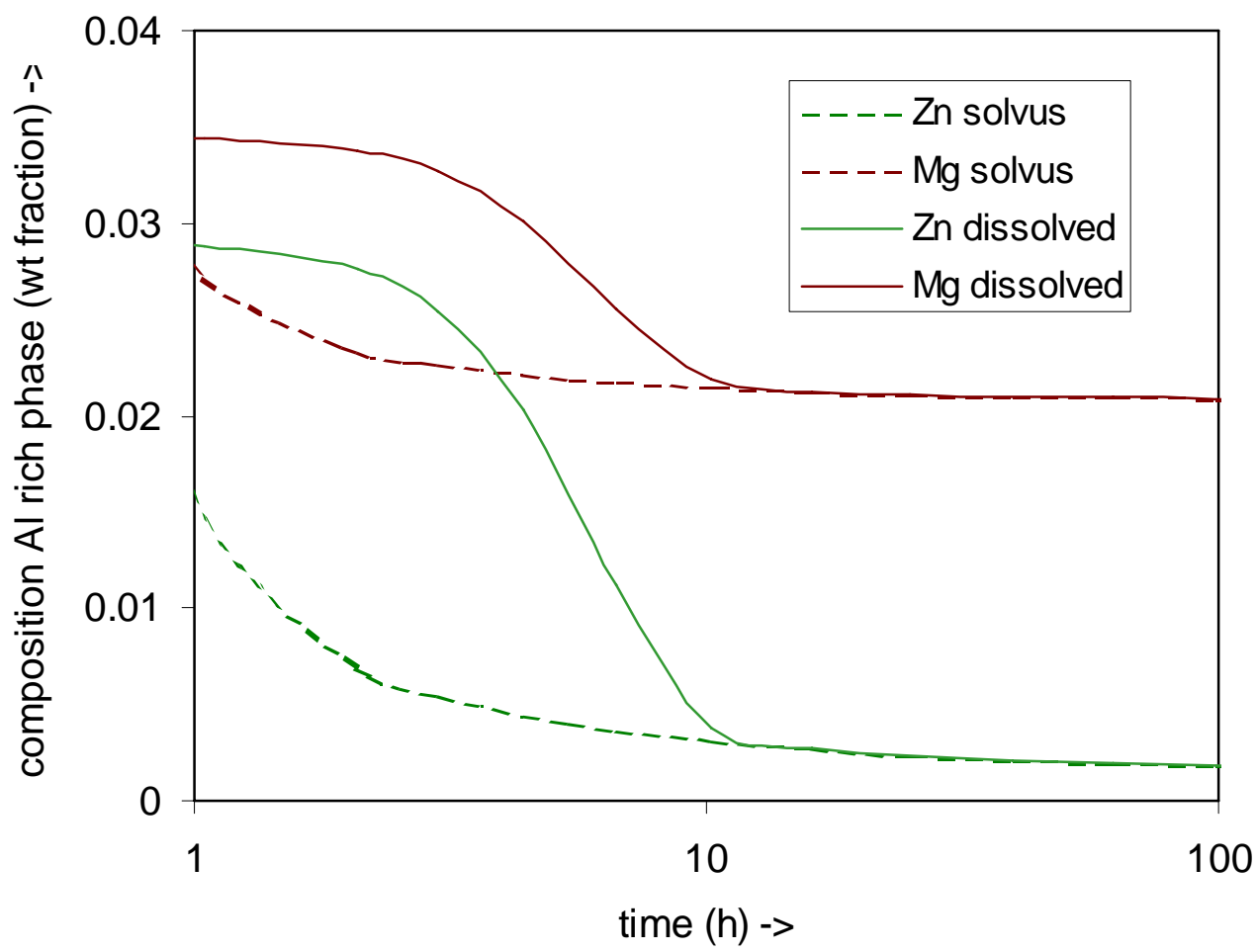

Fig. 11 Composition of the Al rich phase (solid curves) and the metastable solvus for the precipitates of finite size (dotted lines) of the Al-6.7Zn-2.9Mg-1.9Cu alloys during ageing at $172^{\circ} \mathrm{C}$, as predicted by the model.

\section{Discussion}

In the previous section, it was shown that the conductivity model can predict conductivity data on $9 \mathrm{Zr}$-containing alloys and $5 \mathrm{Cr}$-containing alloys very well. In comparing the conductivity model with the microstructural data (TEM, SEM, DSC), it is noted that the main microstructural features in the model, i.e. solute depleted area, intermetallic particles as well as the precipitation in the grain, are confirmed by the TEM, SEM and optical microscopy data. The DSC data in combination with the SAD work indicates that in the material investigated $\eta$ is the dominant precipitate. The gradual disappearance of the last remnant of an exothermic effect superimposed on a broader endotherm in DSC experiments after ageing for about 8 to $16 \mathrm{~h}$ at $172^{\circ} \mathrm{C}$ (Fig. 7) indicates that the transition from precipitation to coarsening is occurring at this stage of the isothermal ageing. This is consistent with the evolution of the solute content of the Al-rich phase predicted by the model (Fig. 11). Thus all the presented microstructure observations as well as data from available literature indicate that the microstructural features of the $7 \mathrm{xxx}$ alloys conform well to the basic elements of the model. However, as a note of caution, it is worth noting that the model is expected not to be able to fit data at very short ageing times, because the very small sizes of the precipitates and/or GP zones will cause scattering of electrons by precipitates to be an important mechanism influencing conductivity [10]. However, most 7xxx alloys for commercial use 
are aged for well over $4 \mathrm{~h}$ at a temperature close to the one used in the present work, and, hence, the present model is applicable to the modelling of conductivity of 7xxx alloys in most commercial tempers, even though it may fail for underaged alloys.

It is observed that the parameters obtained from the best fit are different for Cr-containing alloys and Zr-containing alloys; especially $\sigma_{0}$ appears to be significantly different. This is thought to be mainly due to a combination of a substantial Cr solubility in the Al-rich phase and a high $r_{C r}$ ( $\mathrm{Cr}$ has the larges the $r$ value of all common alloying elements of aluminium alloys [26]). The magnitude of this effect can be obtained from the following equation, which gathers the effects of minor alloying element and main impurities on $\sigma_{0}$ :

$$
\sigma_{o}^{-1} \cong \rho_{A l}+r_{Z r} x_{Z r}(t)+r_{C r} x_{C r}(t)+r_{F e} x_{F e}(t)+r_{S i} x_{S i}(t)
$$

As the solubility of Fe and Si is lower than the amounts of Fe and Si present in our alloys (and most commercial alloys) the amount of $\mathrm{Si}$ and Fe dissolved in the Al-rich phase is similar for all our alloys and independent of Cr content, and thus the contribution of Si and Fe to resistivity should be the same for all alloys. As solubility of $\mathrm{Zr}$ at the solution treatment temperature is extremely small ( $<0.01 \mathrm{at} \%$ ) the influence of $\mathrm{Zr}$ is small and we can derive that the difference between the $\sigma_{0}$ for Cr-containing alloys and Zr-containing alloys should be determined mainly by the amount of Cr dissolved:

$$
\sigma_{o}(7 x x x-C r)^{-1}-\sigma_{o}(7 x x x-Z r)^{-1} \cong r_{C r} x_{C r}(t)
$$

Using $r_{C r}=7.710^{-8} \Omega^{-1} \mathrm{~m}^{-1}$ [26] we obtain $x_{C r}=0.035 \mathrm{at} \%$, which is very close to the solubility of $\mathrm{Cr}$ for an $\mathrm{Al}-\mathrm{Zn}-\mathrm{Mg}$ alloy at the solution treatment temperature (Cr solubility varies strongly with $\mathrm{Zn}$ content [28,35] and equals about $0.04 \mathrm{at} \%$ at $457^{\circ} \mathrm{C}$ for $\mathrm{Zn}$ and $\mathrm{Mg}$ contents similar to the alloys studied [28]). As diffusivity of $\mathrm{Cr}$ in $\mathrm{Al}$ is very low, precipitation of $\mathrm{Cr}$ during typical ageing treatments is generally not possible, and thus the present assessment indicates that the difference in $\sigma_{0}$ can indeed be ascribed to be due mainly by $\mathrm{Cr}$ dissolved in the Al-rich phase. Apart from this effect $\mathrm{Cr}$ can also have an indirect effect on conductivity through the $\mathrm{Cr}$ containing dispersoids providing nucleation sites for precipitation and by influencing grain structure.

Also a small difference in $k$ value is observed for the two groups of alloys. The main mechanisms causing the difference in $k$ values are thought to be the increased presence of subgrain boundaries and dislocation in alloys with $\mathrm{Al}_{3} \mathrm{Zr}$ particles [55], which would enhance formation and coarsening of precipitates, and trapping of vacancies by $\mathrm{Cr}$ and $\mathrm{Zr}$ atoms, which would reduce coarsening rates. Mukhopadhyay et al [56], indicated that the addition of $\mathrm{Zr}$ to an Al-Zn-Mg alloy retards GP zone and $\eta^{\prime}$ formation and slows down $\eta$ precipitation, whilst other research has suggested an enhancement of artificial ageing [55]. It is believed that the slightly lower $k$ value obtained for the Cr containing 7xxx alloys (Table 2) is mainly caused by increased presence of subgrain boundaries and dislocation in alloys with $\mathrm{Al}_{3} \mathrm{Zr}$ particles; whilst also vacancy trapping by $\mathrm{Cr}$ might be involved.

To further assess the performance of the conductivity model, a comparison of the accuracy of the physically based model with an adaptive numeric modelling process was made. AN 
modelling is a purely mathematical modelling process, i.e. the technique does not take any physical understanding into account. The AN modelling technique used is the neurofuzzy (NF) modelling approach, which was applied to the larger of the two datasets, i.e. the Zrcontaining alloys. For this data, a training error (RMSE) of 0.54\%IACS and test error (RMSE) of 0.61\%IACS was obtained [10,47]. As one might expect from any 'good' physically based model, these results indicate that our physically based model is more accurate than the model constructed by the AN modelling approach. (It should be noted that AN modelling has distinct advantages, which especially come in to play for modelling problems where limited physical understanding is available, where large amounts of data are available and where data is noisy [10]. In some of these cases physically based modelling may be impossible or adaptive numeric modelling may outperform physically based modelling.) Further to the accuracy of the model presented, it should be noted that the accuracy that can be achieved is limited by small variations in the composition of samples which can occur due to some small but unavoidable macro segregation during casting. For instance, for alloys aged for $2 \mathrm{~h}$, a change in the local Mg content of $0.1 \mathrm{wt} \%$ is predicted to lead to a change in local conductivity of $0.4 \%$ IACS, which shows that even quite limited segregation can explain the observed accuracy of about $0.4 \%$ IACS. In concluding this assessment, the accuracy obtained with the current physically based model is though to be close to the best possible that can be achieved, given the limitations of accuracy of composition determination.

Whilst the discussion presented so far indicates that the model is quite successful, and corresponds well to metallurgical understanding, a number of limitations and unresolved issues should also be mentioned. Firstly, it is noted that the impingement parameter obtained in the fitting procedure indicates that the precipitation process follows JMAK kinetics. Whilst some authors in the past have assumed JMAK kinetics to be valid for precipitation, recent work $[48,49,50]$ has shown that JMAK kinetics is generally not valid for these reactions and that instead Eq. (26) with $\eta_{i}$ between 0.5 and 2 fits precipitation reactions. This apparent contradiction is, as yet, unresolved, however, it is noted that the determination of $\eta_{i}$ in the present work is an indirect one and that the more direct $\eta_{i}$ determinations in the works mentioned above are more reliable [48,49,50].

Further on the issue of possible flaws and limitations of the model, it is noted that we have compared the present model predictions with data from Dorward [11] on the conductivity of a 7050 alloy that was pre-aged at $120^{\circ} \mathrm{C}$ and subsequently aged at $172^{\circ} \mathrm{C}$. It was found that the present model overpredicts that conductivity data by about $2 \%$ IACS, and this poor correspondence might indicate that pre-ageing has an influence, which is overlooked in the present model. However, as impurity levels are known to have a significant influence on the conductivity of unalloyed $\mathrm{Al}$, it is thought that differences in the impurity levels of the alloys has a stronger influence. Dorward's 7050 alloy indeed has somewhat higher measured Si, Fe and Ti levels (0.05, 0.07 and $0.03 \mathrm{wt} \%$, respectively) as compared to our alloys (on average $0.025,0.065$ and $0.02 \mathrm{wt} \%$, respectively). Data on other impurities is not available, but we suspect these might also be more abundant in Dorward's 7050 alloy. Especially elements in groups IVA to VIIIA have a high value of $r$ [26] and thus of the minor alloying elements and common impurities especially $\mathrm{Ti}, \mathrm{Cr}, \mathrm{Mn}, \mathrm{Fe}$ and V can have a significant influence on 
conductivity. (Maximum levels of Ti, Cr, Mn and Fe specified for selected 7xxx alloys are presented in Table 1.) Further indications for the influence of purity can be obtained from data on conductivity of 7x75 type alloys. For these alloys, both the purity and conductivity in T6, T73 and T76 type tempers increase in the sequence 7075, 7175, 7475, whilst the content of main alloying elements is about constant (see data in [57]). The difference in conductivity between 7075 and 7475 in equivalent tempers ranges from 1.5\%IACS to 3\%IACS, and these differences are in line with differences found between model predictions calibrated against our alloys and data on Dorward's 7050 alloy. Nevertheless, the differences in the Fe, Si and Ti contents is limited, and it is not clear whether these differences and differences in contents of other impurities are the main cause for the difference in conductivity. A third factor to consider is the grain structure. Figure 4 shows that all our alloys were partly recrystallised, and this might have been different from Dorward's 7050 alloy (for instance because $\mathrm{Zr}$ content in our alloys is higher) but no assessment of grain microstructures was presented in his paper.

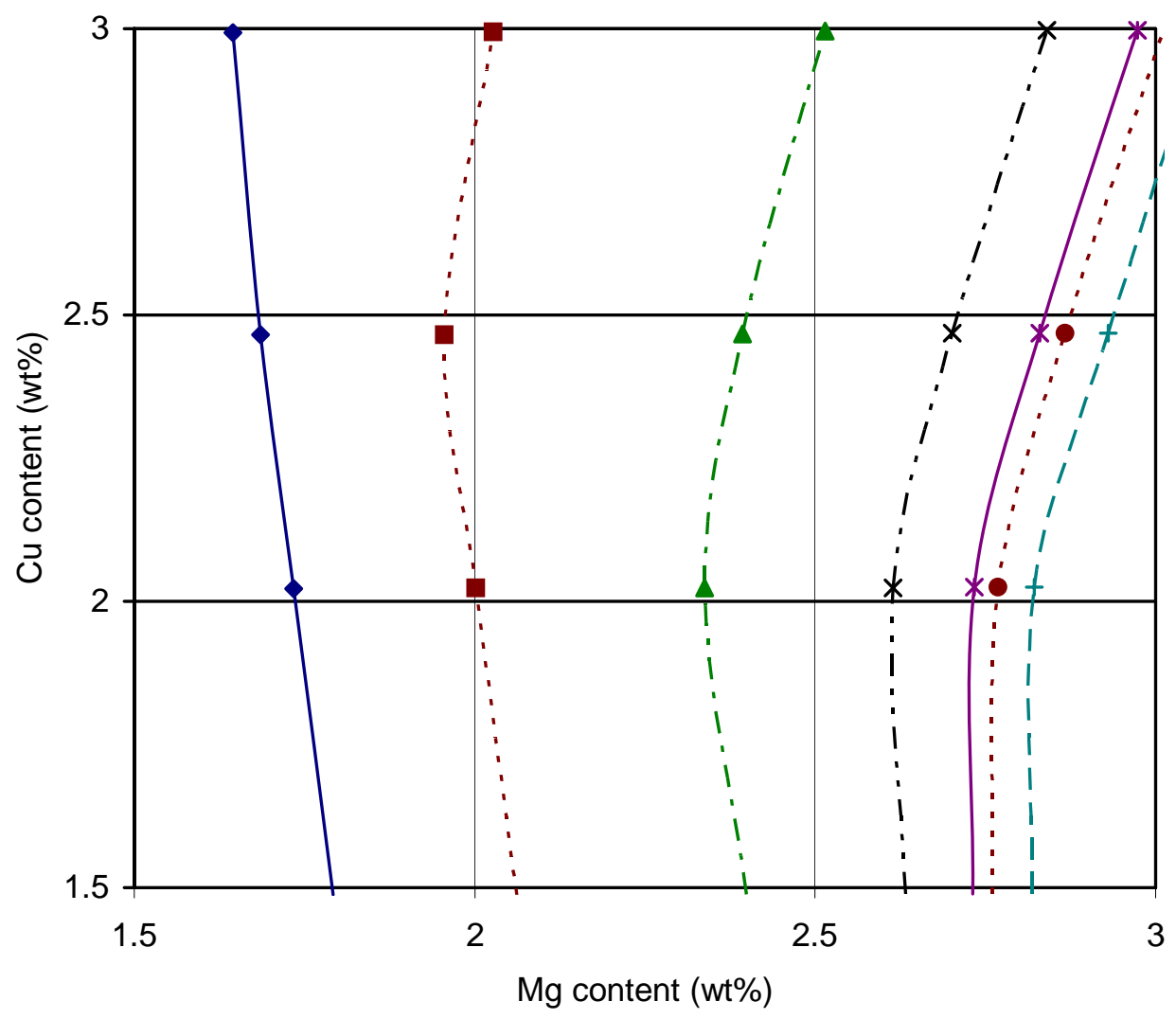

Fig. $12 \mathrm{Cu}$ content and $\mathrm{Mg}$ content required to attain a conductivity of 39.5\%IACS for $\mathrm{Zr}$ containing alloys containing $6.2 \mathrm{wt} \% \mathrm{Zn}$ for various ageing times. Curves represent (from left to right) 2, 4, 6, 8, 10, 12 and $48 \mathrm{~h}$ ageing at $172^{\circ} \mathrm{C}$.

It is also noted that the values of $r_{M g}, r_{Z n}$ and $r_{C u}$ obtained by the fitting process (see Table 2) in general do not correspond to values determined for binary alloys as given in Ref. [24]. In 
particular the finding that $r_{M g}$ is at least 4 times larger than either $r_{Z n}$ and $r_{C u}$, thus causing the $\mathrm{Mg}$ content of the alloy to dominate the conductivity, is inconsistent with data for binary alloys in Ref. [24]. This may indicate that deviations from additivity occur, i.e. interactions between dissolved atoms could be invalidating Mathiesen's rule (Eq. 10). Another possible reason could be that the present model is overlooking an additional mechanism relating composition to conductivity, for instance the scattering of conducting electron by small particles. This mechanism may be partly responsible for the deviations between Dorward's data and our model predictions, especially because pre-ageing can cause precipitates to be finer. However, it would be unclear as to how composition could have a substantial influence on this mechanism, such that it would explain the observed deviations of $r_{M g}, r_{Z n}$ and $r_{C u}$ obtained by the fitting process from the values determined for binary alloys.

Irrespective of which type of interaction, or secondary mechanisms, might have been overlooked in the present model, it is clear that the model provides a very good prediction of the influence of ageing time, composition and microstructure on conductivity and is consistent with the microstructural data presented. The model is valuable because it is able to explain conductivity variations quantitatively and on a physical basis; and is also valuable in an industrial context, especially if models for prediction of other key properties (strength, toughness) can be derived. In fact, the modelling of yield strength in the present set of alloys is the subject of current work by the present authors [36].

\section{Conclusions}

In the present paper, optical microscopy, SEM/EDS, TEM and DSC were employed to study the microstructures of Al-Zn-Mg-Cu 7xxx alloys. The microstructural data is used to support the derivation of a detailed conductivity model for 7xxx aluminium alloys, which takes account of the conductivity of grains (incorporating dissolved alloying elements, undissolved particles and precipitates), grain boundaries and solute depleted area. It has been successfully used to model the conductivity data of 14 7xxx alloys. For Zr-containing 7xxx alloys, 9 alloys aged at $172^{\circ} \mathrm{C}$ were modelled. The measured conductivity data contains 36 points with 4 various ageing times. The model fits well to the measured conductivity with root mean square error (RMSE) about 0.44\%IACS. For Cr-containing 7xxx alloys, 5 alloys aged at $172^{\circ} \mathrm{C}$ were modelled. The model fits the data with RMSE about $0.41 \%$ IACS. The values of the main model parameters can be rationalised on the basis of metallurgical understanding and previous data.

\section{Acknowledgements}

The authors would like to acknowledge the financial support from Alcoa Europe, Birmingham, UK (formerly British Aluminium Plate). The alloy production and electrical conductivity measurements were performed at QinetiQ (formerly DERA), Farnborough, UK. Valuable technical discussions with Drs. J. Newman and S. Waters (Alcoa Europe) and Dr P.D. Pitcher (QinetiQ) are gratefully acknowledged. 


\section{References}

1 Polmear, I. J.: Light Alloys-Metallurgy of the Light Metals, $3^{\text {rd }}$ ed., St. Edmundsbury Press Ltd, Bury St Edmunds, Suffolk, UK, 1995

2 Sarkar, B., Marek, M., and Starke, E. A., 1981, Metall. Trans. A, vol. 12A, pp. 1939-1943.

3 Tsai, T. C. and Chuang, T. H., 1996, Metall. Mater. Trans. A, vol. 27A, pp. 2617-2627.

4 Tsai, T. C., Chuang, J. C., and Chuang, T. H., 1997, Metall. Mater. Trans. A, vol. 28A, pp. 2113-2121.

$5 \quad$ Hepples, W., PhD thesis, University of Newcastle Upon Tyne, UK, 1987.

6 Tsai, T. C. and Chuang, T. H., 1996, Corrosion, vol. 6, pp. 414-416.

7 Davis, J.R. (ed): Aluminium and Aluminium Alloys, ASM Specialty Handbook, $3^{\text {rd }}$ ed., ASM International, Materials Park, OH, USA, 1993

8 Park, J.K. and Ardell, A.J., 1991, Acta Metall. Mater., vol. 39, 591-598.

9 Bratland, D. H., Grong, O., Shercliff, H., Myhr, O. R., and Tjotta, S., 1997, Acta Mater., vol. 45, pp. 1-22.

10 Guyot, P. and Cottignies, L., 1996, Acta Mater., vol. 44, pp. 4161-4167.

11 Dorward, R. C., 1999, Mater. Sci. Tech., vol. 15, pp. 1133-1138.

12 Femminella, O. P., Starink, M. J., Brown, M., Sinclair, I., Harris, C. J., and Reed, P. A. S., 1999, ISIJ International, vol. 39, pp. 1027-1037.

13 Femminella, O. P., Starink, M. J., Gunn, S. R., Harris, C. J. and Reed, P. A. S., 2000, Mater. Sci. Forum, vol. 331-337, pp. 1255-1260.

14 Cumbrera, F. L., and Sanchez-Bajo, F., 1995, Thermochim. Acta, vol. 266, pp. 315-330.

15 Cahn, R. W., Haasen, P., and Kramer, E. J.: Materials Science and Technology-Structure and Properties of Nonferrous Alloys, VCH Publishers Inc., New York, USA, 1996.

16 Deschamps, A., Livet, F., and Brechet, Y., 1998, Acta Mater., vol. 47, pp. 281-292.

17 Deschamps, A., and Brechet, Y., 1998, Acta Mater., vol. 47, pp. 293-305.

18 C.H.J. Davies, N. Raghunathan, and T. Sheppard, 1994, Acta Metall. Mater., vol. 42, pp. 309318.

19 Wert, J. A., 1981, Scr. Metall., vol. 15, pp. 445-447.

20 Maloney, S. K., Hono, K., Polmear, I. J., and Ringer, S. P., 1999, Scr. Mater., vol. 41, pp. 10311038.

21 Deschamps, A., Brechet, Y., Guyot, P. and Livet, F., 1997, Z. Metallkd., vol. 88, pp. 601-606.

22 Li, X. and Starink, M. J., 2000, Mater. Sci. Forum, vol. 331-337, pp. 1071-1076.

23 Machler, R., Uggowitzer, P. J., Solenthaler, C., Pedrazzoli, R. M., and Speidel, M. O., 1990, J. Inst. Metals, pp. 447-451.

24 Hatch, J. E.: Aluminium: Properties and Physical Metallurgy, American Society for Metals, Ohio, 1983.

25 Olafsson, P., Sandstrom, R., and Karlsson, A., 1996, Mater. Sci. Forum, vol. 217-222, pp. 981986.

26 Brown, R.H. and Willey, L.A., in Aluminium Vol 1, K.R. Van Horn, ed, ASM, Metals Park, Ohio, 1967

27 Li, X. and Starink, M. J., 2001, Mater. Sci. Techn., vol. 17, pp. 1324-28.

28 Mondolfo, L. F.: Aluminium Alloys: Structure and Properties, Butterworth \& Co. Ltd, London, England, 1976.

29 Starink, M. J. and Gregson, P. J., 1995, Mater. Sci. Lett., vol. 14, pp. 1767-1769.

30 Starink, M. J., Starink, L.M.P. and Chambers, A.R., 2002, J. Mater. Sci., vol. 37, pp. 287-294

31 Morris, A. J., Robey, R. F., Couch, P. D., and Rios, E. D. L., 1997, Mater. Sci. Forum, vol. 242, pp. 181-186.

32 Warner, T. J., Shahani, R. A., Lassince, P., and Raynaud, G. M., 1997, $3^{\text {rd }}$ ASM Conf. On Synthesis, Processing and Modelling of Advanced Materials, Paris, France.

33 Liang, H., Chen, S. L., and Chang, Y. A., 1997, Metall. Mater. Trans. A, vol. 28, pp. 1725-1734.

34 Liang, P., Tarfa, T., Robinson, J. A., Wagner, S., Ochin, P., Harmelin, M. G., Seifert, H. J., Lukas, H. L., and Aldinger, F., 1998, Thermochim. Acta, vol. 314, pp. 87-110. 
35 Villars, P., Prince, A., and Okamoto, H., 1995, ASM Handbook of Ternary Alloy Diagrams, ASM International, Materials Park, Ohio.

36 Li, X., PhD thesis, University of Southampton, 2002

37 Starink, M. J. and Gregson, P. J., 1995, Scr. Metall. Mater., vol. 33, pp. 893-900.

38 Starink, M. J. and Gregson, P. J., 1996, Mater. Sci. Forum, vol. 217-222, pp. 673-678.

39 Strawbridge, D. J., Hume-Rothery, W. and Little, A. T., 1948, J. Inst. Metals, vol. 74, 191.

40 Rayleigh, L., 1892, Philos. Mag., vol. 34, pp. 481.

41 Gupta, M., Karunasiri, G. and Lai, M. O., 1996, Mater. Sci. Eng. A, vol. A219, pp. 133-141.

42 Bigot, A., Danoix, F., Auger, P., Blavette, D. and Reeves, A., 1996, Mater. Sci. Forum, vol. 217222, pp. 695-700.

43 Stiller, K., Warren, P.J., Hansen, V., Angenette, J. and Gjønnes, J., 1999, Mater. Sci. Eng. vol. A270, pp. 55-36.

44 Deschamps, A., Bigot, A., Livet, F., Auger, P., Brechet, Y. and Blavette, D., 2001, Philosoph. Mag. vol. 81, pp. 2391-2414.

45 Li, X. Z., Hansen, V., Gjonnes, J. and Wallenberg, L. R., 1999, Acta Mater., vol. 47, pp. 26512659.

46 Starink, M. J., Sinclair, I., Reed, P. A. S. and Gregson, P. J., 2000, Mater. Sci. Forum, vol. 331337, pp. 97-110.

47 Poduri, R. and Chen, L.-Q., Acta Mater., 1998, vol. 46, pp. 3915-3928.

48 Starink, M. J. and Zahra, A. M., 1997, Thermochim. Acta, vol. 292, pp. 159-168.

49 Starink, M. J. and Zahra, A. M., 1998, Philosoph. Mag., vol. A77, pp. 187-199.

50 Starink, M. J. and Zahra, A. M., 1998, Acta Mater., vol. 46, pp. 3381-3397.

51 Kamp, N., Sinclair, I. and Starink, M.J., 2001, Metall. Mater. Trans A, vol 33A, pp. 1125-1136

52 Park, J.K. and Ardell, A.J., Metall. Trans. A, 1983, vol. 14A, pp. 1957-1965.

53 Deschamps, A., and Brechet, Y., Scr. Mater., 1998, vol. 39, pp. 1517-1522.

54 Kanno, M., Iraki, I., and Cui, Q., 1994, Mater. Sci. Techn., vol. 10, pp. 599-603

55 W. Lacom and H. P. Degischer, Thermochimica Acta, Volume 119, Issue 1, 15 September 1987, Pages 211-218 .

56 Mukhopadhyay, A. K., Shiflet, G. J., and Starke, E. A. Jr., 1990, Scripta Metall. Mater., vol. 24, pp. 307.

57 ASM Specialty Handbook: Aluminum and Aluminum Alloys, J.R. Davis \& Ass. (Ed.), (ASM International, Materials Park, OH, USA, 1993) 